\title{
PHARMACEUTICAL PREPARATIONS.
}

We have received from Messrs. Burroughs Wellcome and Co. a specimen of "Tabloid" brand Blaud Pill, gr. 8, which is now issued to meet the demand for a preparation containing a dose larger than 4 grains, the strength of the present product.

“ Tabloid " Blaud Pill does not contain preformed ferrous carbonate. The ferrous sulphate and sodium carbonate are mixed in such a way that interaction does not take place until the "Tabloid" product commences to dissolve in water or in the gastric juice. Ferrous carbonate, in the form of pills or powders, even when every ordinary precaution is taken, slowly undergoes conversion to oxide. No such oxidation can take place in "Tabloid" Blaud Pill, the ferrous carbonate being formed in the gastric juice itself. "Tabloid" Blaud Pill thus constitutes a generally effective means of administering the most readily assimilated salt of iron.

Mr. E. J. Reid, of Basinghall Street, E.C., has sent us samples of Iodine Vasogen. This consists of iodine 6 per cent. and vasogen 94 per cent., and it is a preparation deserving of extensive trial. It is made in two strengths, 6 per cent. and 10 per cent., but the 6 per cent. is that more generally used. It contains pure iodine in solution, and penetrates the skin more rapidly than other preparations of iodine. As a substitute for tincture of iodine it has been found to be most useful, as it does not irritate the skin, and is practically stainless. 


\section{INDEX TO VOL. XV., 1900.}

Abductor paralysis, bilateral (Wyatt Wingrave) intra-inuscular injections (L. H. Pegler) sinulated by compression of the trachea by aneurism of the arch of the aorta (Courtade : abstract)

Abscess: case of abscess round the sigmoid sinus without suppuration of the mastoid (Professor Politzer) cerebellar (Rimini : abstract) (Dieulafoy : abstract) due to otitis : two cases, one cured (Hansberg : abstract). following chronic middle-ear suppuration, specimens (W.

Milligan)

following otitis suppurativa (Bonain : abstract) . operated upon (W. Milligan) sequestration of cochlea in cured case (i. B. Waggett) (cerebral) and mastoid disease in case of suppurative otitis: necropsy (H. Blake : abstract)

formation of a circumscribed inter-dural abscess at the site of the saccus endolymphaticus (IV. Jobson Horne)

- large subperiosteal, over base of mastoid process (Dr. Hasslauer : abstract)

- of antrum : asthma as reflex manifestation from (Richardson:

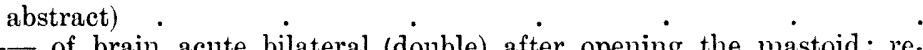
covery (H. Seligman: abstract).. .230 rare case due to otitis (W. Lindt, jun.: abstract) $\quad .451$ of occipital part of brain of otitic origin (Heiman : abstract) $\quad .402$ (orbital) with frontal sinus empyema (Martin : abstract) . 105 multiple, of tonsils, in pharyngeal and naso-pharyngeal diphtheria

(Sendziak : abstract) peritonsillar (Sendziak : abstract) with hæmorrhage (IV. F. Chappell) retropharyngeal (Traver: abstract) of auricular origin (Urbano Melzi) temporal, of otitic origin (A. Broca : abstract)

- tonsillar and circumtonsillar abscess (G. A. Leland : abstract) . 328 403

Abstracts of literature: diphtheria, etc.

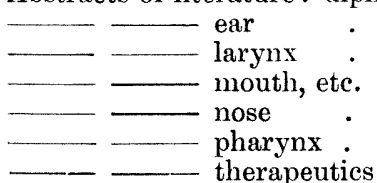

$94,287,327,394,439,614$ $56,107,223,342,402,567,618,672$ $51,97,218,290,336,399,444,511,668$ $46,96,210,287,327,395,439$ $47,97,212,289,331,397,441,510,617,667$ $231,624,675$

Acoumetric notation (Pierre Bonnier) • . . . 286

Acoumetry, a universal notation (F. Schiffers, and A. Hartmann) $\quad 556,558$

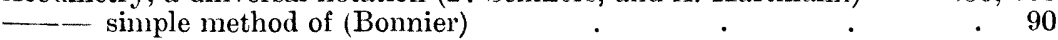


Acoustic exercises for deaf-mutes (V. Crbantschitsch and I). Schwendt) 559 , 560

Adeno-carcinoma : removal of large part of auricle and whole of meatus for adeno-carcinoma (A. Cheatle)

Adeno-sarcoma of nasal septum (Baker: abstract)

Adenoid reflexes: hiccup, photophobia (Thomas: abstract) vegetations (H. Cuvellier)

\section{Adenoids and and diphtheria (Plottier : abstract)}

ds and enlarged tonsils and their removal (D. J. G. Wishart)
degenerated in a woman of sixty-seven (I)r. Ephraim : abstract homorrhage following operations for (Martin: abstract) in cases of chronic purulent nasal discharges (E. W. Roughton) . 241

- in early infancy (Jauquet: abstract) .

operation for adenoid vegetations (Alfred Decker : abstract)

_- post-nasal : auditory results of removal (D. Mc Keown) .

post-nasal growth considered persistence of adenoids (E. Furniss

Potter)

post-nasal, well-marked (StClair Thomson)

removal benefiting epilepsy (L. Browne)

Adhesion, complete, of the epiglottis with the root of the tongue through luetic cicatrices (Rischaevay: abstract).

- pseudo-membranous, in anterior commissure (Sir Felix Semon) 256

Adrenal extract: successful application in rhinology (Warren : abstract) . 444

Adults (elderly), special danger of acute purulent suppuration of ear in (B. Heine : abstract)

(young), treatment of simple goitre in (Murray : abstract)
Atiology of phlegmonous peritonsillitis, importance of upper portion of tonsil and of supratonsillar fossa in (R. Botey) . .

Alkin (W. A.), the resonators of the voice . $\quad . \quad$. 426

Air (hot), in treatment of nasal and naso-pharyngeal affections (M. Lermoyez and G. Mahu)

Air-douche, negative, as aid to diagnosis of diseases of nasal accessory cavities (L. Réthi : abstract) .

Air-passage : opening of air-passage in two cases of cut throat $(\mathbf{E}$, R. C.

Earle : abstract) upper air-passages (Sokolowski : abstract) lowski : abstract)

Ala nasi: see Nose.

Allas (C. M.), a suggestion as to the treatment of Grares' disease by the administration of bile by the mouth, hypodermically and intrathyroideal, with cases (abstract).

Alt (Dr.), case of sarcoma growing from the middle ear in a boy of five (abstract).

Anæmia (pernicious), diseases of ear in (Schwabach : abstract) .

Anæsthesia: experiments in anæsthesia of the semilunar canals of the ear (Professor G. Gaglio)

of semicircular canals of ear, experiments on ( $\dot{\text { G. Gaglio) }} \dot{\text {. }}$

of soft palate in case of hysterical paralysis of left vocal cord (C.

Chaveau).

(local) production in ear (A. A. Gray: abstract)

Anæsthetics (D. W. Buxton: review)

Anatomy of ear (Cole: abstract)

of frontal sinus and anterior ethmoidal cells (A. Hartmann)

of petro-squamosal sinus (A. H. Cheatle)

pathological, of middle ear and labyrinth (H. Haike : abstract)

Anprewes (F. W.), a discussion on the pathological distribution of the diphtheria bacillus and the bacteriological diagnosis of diphtheria (Brit. Med. Assoc. Annual Meeting, Section of Pathology) 


\section{Index.}

Andrews (Albert H.) and Hial (G. P.), the year-book of the nose, throat, and ear (review)

Aneurism, aortic, early diagnosis and treatment (M. Schmidt : abstract) : abstract) application of Röntgen's rays in examination of (Sendziak :

- of the arch of the aorta simulating paralysis of the abductors by compression of the trachea (Courtade : abstract) .

Angina, chancriform (Mariau : abstract)

diphtheritic and ulcerous, with fusiform bacilli and the spirille of

Vincent; clinical and bacteriological study (J. Freyche : abstract)

- erosive, after scarlatina (Bergé : abstract)

- (lacunaris), an epidemic of, and period of incubation (Siegert: abstract) .

- membranous, of doubtfully diphtheritic nature occurring in patient convalescing from scarlet fever (Millard: abstract) (simple), an epidemic due to streptococcus (L. Le Damany : abstract) ulcerous, so-called: its differential diagnosis from diphtheria

(Raczynski : abstract)

- ulcero-membranous chancriform, with Vincent's fusiform bacilli and spirillæ (A. Panoff : abstract)

ulcerosa benigna (A. H. Kelly : abstract)

Angioma (cavernous), of the external auditory meatus (Hennebert: abstract) 206

- multiple angiomata of the tongue (Morelli) . $\quad$. $\quad 326$

$\begin{array}{llll}\text { Angio-sarcoma of nasal septum (Herbert Tilley) } & . & . & 265,369\end{array}$

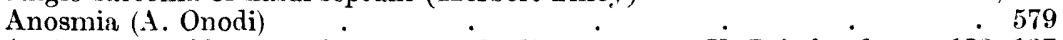

Antiseptic purification of meatus and adjacent parts (U. Pritchard) 123, 137

Antitoxin: diphtheritic paralysis in cases treated with (F. J. Woolacott: abstract)

of diphtheria : strength and preservation (Tavel : abstract) serums for diphtheria

Antrum (abscess): asthma as reflex manifestation from (hichardson: abstract) . . . . . - antral affection of uncertain character causing obstruction of one nostril (StClair Thomson)

- disease: sequestration of bone around lumen of canal formed by drilling alveolus in antral disease (Lichtwitz)

empyema: double frontal sinus and antral empyema, with distension of bridge of nose (H. Tilley)

$$
\text { empyema, new instruments for treatment (Mr. Acland). }
$$
treatment (E. W. Roughton) palpation of maxillary antrum and endo-nasal operation

for (Dr. Kaspariant) empyemata of both antra of Highmore in diphtheria of pharynx and naso pharynx (Sendziak : abstract)

Aorta (aneurism), application of Röentgen's rays in examination of (Sendziak : abstract)

- - causing simulated abductor paralysis by pressure on trachea

(Courtade : abstract) .

early diagnosis and treatment (M. Schmidt : abstract) $\quad 341$

APERT, cancer of the cesophagus spreading to the trachea (abstract) . 511

Aphonia and hoarseness of long standing in a girl aged thirteen (P. de Santi) 264 boy aged ten suffering from (E. W. Roughton) intractable, with occasional apsithyria (L. H. Pegler) . $\quad$. 156

Apsithyria, occasional, in case of intractable aphonia (L. H. Pegler) . 156

Architecture of laryngeal cartilages (Max Scheier) . $\quad . \quad 601$

Argyrism of skin and mucous membranes due to repeated cauterization of pharynx with silver nitrate (Méneau : abstract) . $\quad . \quad 105$

Armstrong on the thyroid duct: its removal (abstract) . $\quad 218$ 
Artery (carotid): removal of portions of carotid arteries, together with sarcoma of carotid sheath (Scanes Spicer and Stansfield Collier: abstract) visible through perforation of membrana tympani in girl aged seventeen (Dr. Marx)

Arthritis, laryngeal (Escat)

Artillery practice, effect on the ears ( $R$. Miiller : abstract

Ary-epiglottic fold: epithelioma (Wyatt Wingrave) Grant)

growth in neck associated with cedema of (.). Dundas

Arytænoid : case of growth from arytænoid region in male aged fifty-six (R. Lake)

Asch's operation for deflections of the cartilaginous septum (Thorner: abstract) . . . . .

AscHOFF (L.), otitis media neonatorum-a contribution to the embryology of the middle ear (abstract)

Ashton spray, the

Association of German Scientists and Physicians-Section of Laryngology and Rhinology, proceedings . . . .

Asthma as reflex manifestation from abscess of antrum (Richardson: abstract)

Atresia, acquired, of auditory meatus (H. Schwartze : abstract) . - of the larynx in case of chronic pemphigus of the mucous membranes of upper air-passages and of the conjunctiva (Otto : abstract) . (osseous) of the choana: radical operation (Flatau : abstract) .

Atrophy of mucous membrane in chronic purulent nasal discharges ( $\mathrm{E}$. W. Roughton).

of pharynx (R. W. Seiss : abstract) . $\quad . \quad+677$

Atropine in treatment of nasal hydrorrhoea (Jermoyez : abstract) $\quad . \quad 677$

Auditory meatus: see Meatus.

Auricle, frost-bitten, model of (Professor Gribner) (A. Cheatle) large part, with whole of meatus, for adeno-carcinoma

serous cyst of (Guranowski : abstract)

Auricular meatus : see Meatus, auricular.

Auscultation, auricular, new method in diagnosis of central mastoiditis (Ostino: abstract) . . . . . .

Ausset (E.), case of dyspnoea of two vears duration in a girl aged three and $a$ half (abstract).

AUSSET and SEVESTRE, laryngitis complicating measles (abstract)

Auto-intoxication, importance in periodic and aperiodic coryza (Dr. Mounier)

Aviragnet (E. C.), on the treatment of disorders of digestion associated with chronic rhino-pharyngitis and tonsillitis (abstract)

Buber (E. Cresswell), opening of a discussion on intra-nasal treatment in ear disease .

Bacillus coli and bacillus perfringens causing auricular septicæmia (Baup and Stanculéanu: abstract) . . . . - Löfler's : presence of short variety in exudate of ulcero- or erosomembranous tonsillitis following operation (Glover: abstract)

F of diphtheria, pathological distribution (discussion opened by F. W. Andrewes, Brit. Med. Assoc.)

- of Friedländer causing recurring membranous faucitis (Emil Mayer)

of Vincent, fusiform, in case of ulcerous tonsillitis, and in two cases of peribuccal ulceration (Lichtwitz and Sabrazès)

bacteriological examination of four cases of atrophic rhinitis (Meslay and S. Viollet : abstract) .

Bacteriology: bacteriological diagnosis of diphtheria (discussion opened by F. W. Andrewes, Brit. Med. Assoc.) of genuine acute exudative middle-ear inflammation (Nadoleczny : abstract) 


\section{Index.}

Bacteriology of complications of acute and chronic middle-ear suppuration (Leutert-Konigsberg: abstract)

- of normal nose (StClair Thomson)

BAKER, adeno-sarcoma of nasal septum (abstract)

BALL (James Barry), case of papillomatous condition of tongue

BALLANCE (Charles A.), on certain affections of the ear: observations on the recognition of aural diseases in medical practice. In vol. vii. of

"A System of Medicine," edited by T. Clifford Allbutt (review) purulent otorrhuea, with special referense to the immediate healing of the cavity in the bone left by the operation by means of epithelial grafts on epithelial grafting of labyrinth case of alveolar sarcoma, involving petrous bone, and causing paralysis : successful operation .

Bar (Dr.) and Texier (Dr.), contribution to the study of nasal tuber. culosis

Barbon (Lubet) and Furet, on study of fronto-maxillary sinusitis (abstract)

BaroN (Barclay), demonstration of middle-aged man with discharge of pus and blood from naso-pharynx for over twelve months, and with deafness of right ear for twelve months

Barr (T.) and Nicoll (J. H.), cases of thrombosis of the lateral sinus consequent upon purulent infiammation of middle ear; opening of sinus ; ligature of internal jugular vein ; recovery (abstract)

BaUdouin (G.), on chancre of the palate (abstract)

BAUMGaRTEN on primary scleroma of the larynx

Baup and Stanculéanu, auricular septicimia due to bacillus coli and bacillus perfringens (abstract)

BAURowicz, contribution to the etiology of the so-called chorditis vocalis inferior hypertrophica (abstract) the more important cases from the clinic of Professor Pieniazek for diseases of the larynx, throat, and nose in the Hospital of St. Lazar (abstract)

BAYER, on foetid breath and intratracheal injections of carbonate of creosote (abstract) .

BAZIN (A. T.), on persistence of the lower portion of the thyroglossal duct (abstract) .

BERGÉ, on erosive angina fter scarlatina (abstract)

BERGEAT (Dr.), rhinoscopia externa (recessûs apicis nasi) (abstract)

Berger (P.), dentiferous cyst of superior maxilla (abstract) . complete rhimoplasty (abstrat)

BERtin (Mr.), specimen mounted to show ulceration of false cords, true cords, and inter-arytenoid region (shown for Mr. Lake) - specimen showing tubercular ulceration of larynx (shown for Mr. Lake) .

Bernard (M.) and Garex (J.), laryngeal nodules $\cdot{ }^{*} \cdot$

Bernherm (S.), primary tuberculosis of the larynx : .

BEZOLD's complication of suppurative mastoiditis, case of (F. Waggett) mastoiditis: see Mastoiditis.

BIEHL, extensive transference of thrombotic material in a retrograde direction after otitic thrombo-phlebitis of the left sigmoid sinus (abstract) .

BIERNACKI, intubation (abstract)

Bile, administration of, in treatment of Graves' disease (C. i. Allan: abstract)

Binc( Dr.), on Gellé's test (abstract)

BIRD, remarkable accident to superior maxilla (abstract)
BLAKE (Henry), suppurative otitis ; mastoid disease ; cerebral abscess ; necropsy (abstract)

Bleeding and refrigerants in treatment of acute otitis media (Miot: abstract)

BLoch (Dr.), empyema of mastoid antrum (abstract) .

Blood and pus discharged from naso-pharynx for over twelve months (Barclay Baron)

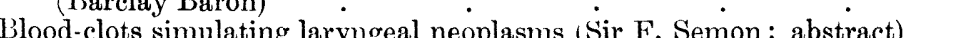


Bloodless operation in cases of typical naso-pharyngeal polypi (Schmithuisen : abstract)

BoENNINGHAUS (G.), the magnifier in otoscopy (abstract)

BoNaIN, cerebellar abscess, etc., following otitis suppurativa (abstract) : 445

Bone: bony cyst of middle turbinate bone (H. Tilley) . _ . . 154

bony spur from ethmoid (R. Lake)

defects in mastoid: method of closure (von Mosetig-Moorhof :

abstract)
$\ldots$ petrous, involved in alveolar sarcoma, causing paralysis : operation (Charles A. Ballance)

- sequestration of bone around lumen of canal formed by drilling

alveolus in antral disease (Lichtwitz)

\begin{tabular}{l} 
— temporal, from a case of leukæmia (Dr. Gomperz) \\
\hline - turbinal, suppurative cyst of (H. J. Davis)
\end{tabular}

BONNIER, a simple method of acoumetry . . . .

- acoumetric notation $\quad . \quad 5 \quad \cdot \quad \cdot \quad \cdot 286$

BoorH (Burton S.), on nasal stenosis (abstract) $\quad . \quad$. $\quad .331$

Birard and Poncet (A.), on the so-called glandular form of cancer of the pharynx (abstract)

BosworTH (F. H.), the treatment of purulent ethmoiditis :

BOTEY (Ricardo), some small modifications of the tracheotomy tube (abstract)

on vocal troubles in singers and their treatment (abstract)

- early suture of the retro-auricular incision after the mastoid opera-

tion (abstract)

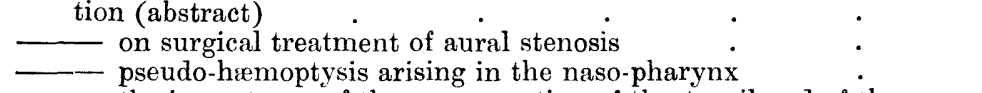

- the importance of the upper portion of the tonsil and of the supra-

tonsillar fossa in the cetiology of phlegmonous peritonsillitis. Extirpation of the upper half of the tonsil the only effectual preventive .

pathogenesis and treatment of laryngeal paræsthesia 5 .

BOVLAI (J.), direct fracture of larynx; stenosis; dilatation; cure - and Boulay (M.), stenosis of larynx treated by electrolysis in a patient who had worn a tracheal cannula sixteen years; removal of cannula

BovlaY (M.) and Boulai (J.), stenosis of larynx treated by electrolysis in a patient who had worn a tracheal cannula sixteen years; removal of cannula

BouRNoviLLE, a case of hysterial cough (abstract)
BowLES (R.) and TURNER (G. R.), on case of rupture of osophagus eaused

by vomiting; table of hitherto recorded cases
Boycan (J. E.), surgery of the turbinal bodies, with a new method of

operating :
Brain (abscess) : acute bilateral (double) brain abscess after opening the
mastoid; recovery (H. Seligman: abstract) _ case of abscess of the occipital part of brain of otitic origin (Heiman : abstract) cerebral abscess and mastoid disease in case of suppurative otitis (H. Blake : abstract)

$$
\text { cerebellar abseess (Dieulafoy: abstract) }
$$

cerebral symptoms wanting in case of profuse escape of cerebrospinal fluid for five weeks (A. Lucae : abstract) able symptoms (A. A. Gray) . . • .

Breath (fœetid): use of intratracheal injections of carbonate of creosote (Bayer: abstract)

Brfiturg (Max), on the prognostic value of Gelle's test (abstract) 
Brindel, on the motor innervation of the soft palate and larynx (abstract)

British Laryngological, Rhinological, and Otological Association: proceedings

\section{annual general meeting}

British Medical Association: annual meeting: Section of Laryngology and Otology Section of Pathology (discussion on " Pathological distribution of diphtheria bacillus," etc.)

Broca (A.), temporal abscess of otitic origin (abstract)

Bromoform treatment of whooping-cough (Feer: abstract)

Bronchus, foreign body in : removal without operation $(H$. von Schrötter : abstract)

abstract) ${ }^{-}$silver cannula fallen into first division of right bronchus (Longbois : abstract)

Bronner (Adolph), case of recurrent papillomata of larynx

Broquet (Charles', on radical cure of chronic maxillary sinusitis by sur gical treatment (abstract)

Browicz, on the internal massage of the mucous membrane of the nose and naso-pharynx (abstract) . . .

Browne (Lennox), on conditions of the throat and larynx simulating and predisposing to tuberculosis

a case of epithelioma of the larynx from which a (presumably) benign neoplasm had been removed nine years previously. - microscopical specimen of growth removed by laryngotomy (shown by Dr. Wyatt Wingrave) adenoids

Bruns (P. V.), resection of the trachea in primary carcinoma (abstract)

Buccal mucosa, "purpura iodique " of (G. Milian : abstract) .

BuISSERET, on surgical treatment of gingivitis (abstract)

Bulb (olfactory), experimental researches (G. Martuscelli : abstract) 215

Bulbar paralysis (E. B. Waggett) . . . . . 203

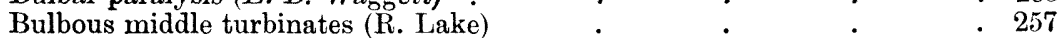

- (J. Payson Clark) • • • • • • • 309

Buller and Byers, case of exophthalmos from empyema of frontal sinus and ethmoid cells; operation; recovery (abstract)

Bullet-wound in head with removal of bullet twenty months afterwards from nose (Claud Woakes : abstract) :

Burt (A. Hamilton), case of a male, aged twenty-nine, with tubercular laryngitis .

Butun (Henry T.), case of cesophageal pouch tion or retention of a tube in the oesophagus

Buxton (Dudley W.), anæsthetics (review).

Byers and Buller, case of exophthalmos from empyema of frontal sinus and ethmoid cells ; operation ; recovery (abstract)

Canals, semicircular, of ear, experiments on anæsthesia of (G. Gaglio)

semilunar, of the ear, experiments on anisthesia of (Professor G. Gaglio)

\begin{tabular}{llll} 
Cancer of larynx (Duvivier : abstract) & $\cdot$ & $\cdot$ & $\cdot$ \\
\hline -Sendziak : abstract) & $\cdot$ & $\cdot$ & $\cdot$ \\
\hline diagnosis (B. Fraenkel) & $\cdot$ & $\cdot$ & $\cdot$ \\
\hline diagnosis (Moritz Schmidt) & $\cdot$
\end{tabular} (Sendziak : abstract) diagnosis (B. Fraenkel) early diagnosis and treatment (J. N. Mackenzie) 
Cancer of pharynx, so-called glandular form of (A. Poncet and Birard: abstract) of trachea and laryax : palliative treatment (A.

primary, of soft palate (Zwillinger) ${ }_{\text {Cannula : silver cannula fallen into first division of right bronchus }}$ (Longbois : abstract)

- (tracheal) use of rubber catheter as tracheal cannula for palliative treatment of cancer of trachea and larynx (A. Courtade)

- (tracheal) worn for sixteen years for stenosis of larynx : removal of

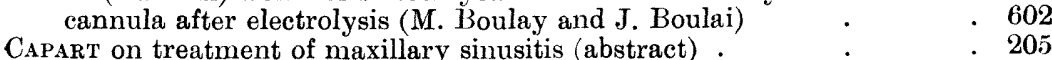

Con singers' nodes..$\quad 5.566$

Carbonic acid in affections of the nose (Joal: abstract) $\quad: \quad 510$

Carcinoma of larynx (V. Navratil) . . . . . . 324

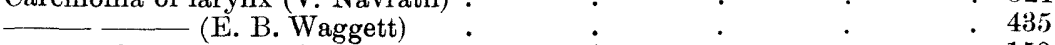

— pharyngo-œsophageal (W. G. Spencer) _ . $\quad .150$

- primary, resection of trachea (Bruns : abstract) . . 400

Carmalt-Jones' spokeshave for removal of septal spurs (W. Gibb: abtrat) spokshave for renoval of septal spurs (WV. Gibb:

Carotid artery : see Artery (carotid).

- sheath: see Sheath (carotid).

Carter (Godfrey), the etiology of Graves' disease (abstract) . $\quad .99$

Cartilage, cricoid: see Cricoid cartilage.

Cartilages, laryngeal, architecture (Max Scheier) . $\quad$. $\quad .601$

(thyroid): see Thyroid cartiluges.
CASTEX on causes and prognosis of facial palsy following operations $\quad .285$

on certain vocal affections.

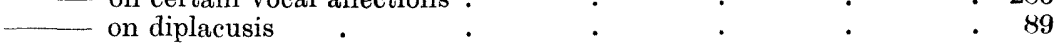

— tonsillar infection revealed by morcellement . $\quad . \quad 89$

Catarrh, catarrhal deafness, so-called, prognosis and treatment (D. Ray) 673 - dry chronic, of the middle ear, in connection with subperiosteal abscess over base of mastoid process (Dr. Hasslauer: abstract) . 403

- nasal, prevention (Rogers: abstract) . $\quad .97$ - painful recurrent, of frontal sinus, due to stenosis of the frontonasal duct (Dr. Luc). . . . .

CathCART (George C.), case of laryngeal affection in a tubereular patient for diagnosis

Catheter, rubber, use as tracheal cannula in treatment of cancer of larynx

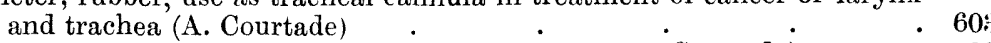

Cauterization, accidental, of larynx by caustic poisons (Courtade) $\quad .93$

-_ of middle ear (Dioniso : abstract) . . . . . . 56 - through ostium maxillare and of frontal sinus in purulent nasal

discharges (E. W. Roughton). 243,244

Cells : anterior ethmoidal, chronic suppuration (P. G. Kingston : abstract) 617

- ethmoidal, anatomy (A. Hartmann). $\quad 64$ abstract) empyema causing exophthalmos (Buller and Byers: abstract) emphysema of orbital wall of anterior ethmoidal cells caused by blowing nose (J. Dundas Grant) $\quad . \quad \cdot{ }^{2} \cdot 163$

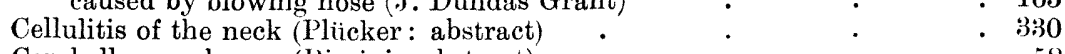

Cerebellum : abscess (Rimini : abstract) $\quad . \quad 5 \quad: 58$ due to otitis: two cases, one cured (Hansberg: abstract) . 110

(V following chronic middle-ear suppuration, specimens

(W. Milligan) • • • • • 137 operated upon (W. Milligan) $\cdot \dot{ } \quad \cdot \quad \cdot \quad \cdot 137$

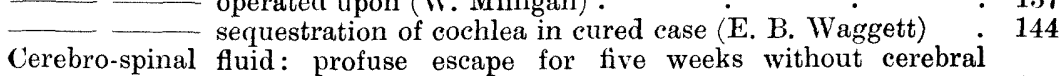
symptoms (A. Lucae: abstract) .0 .452

Chaff-cutter suffering from hoarseness from laryngitis secondary to rhinitis (J. Dundas Grant) . $.0 . .0164$

Chalmers (Albert J.), report on "henpuye" in the Gold Coast Colony (abstract) . 
Champeaux (P. de), on pulmonary lesion due to a benign growth in the larynx (abstract)

Chancre of the palate (G. Baudouin: abstract)

Chancriform angina (Mariau : abstract)

Chappell (W. F.), hæmorrhage from a peritonsillar abscess
Chavead (C.), a case of leucocythæmia symptomatic of a lympho-sarcoma of the tonsil

- hysterical paralysis of the left vocal cord, with concomitant paresis of sterno-mastoid and trapezius of the same side; anæsthesia and paresis of the soft palate, difficulty in swallowing, and hypersecretion

Chearle (Arthur H.), the petro-squamosal sinus: its anatomy and pathological importance

a case of chronic middle-ear suppuration and thrombosis of the lateral sinus, in which the internal jugular vein was not ligatured: recovery - a patient in whom a large part of the auricle and the whole of the meatus had been removed for adeno-carcinoma, and in whom the post-aural operation had been performed, with specimen, and microscopical section - chronic middle-ear suppuration, with thrombosis of the lateral sinus, in which the internal jugular vein was not ligatured: recovery (abstract) .

cases of epithelioma of the meatus and chronic middle-ear suppuration

ChIARI on the prognosis of laryngeal cancer (abstract)

- vocal nodules

Child with curtain-ring in pharynx for eight years (H. L. Lack : abstract).

Children: bleeding and refrigerants in acute otitis media in children (Miot : abstract)

papillomata of larynx in (E. T. Dickerman : abstract) Michel : abstract)

Choana, osseous atresia and radical operation of (Flatau : abstract)
radical operation on bony occlusion of choanc (T. S. Flatau: abstract)

Cholesteatoma, large, removed from mastoid in boy aged fourteen (H. Tilley) $d$ on a modification of Körner's plastic (F. Siebenmann : abstract) removed through meatus ( $\dot{U}$. Pritchard)

Chorditis vocalis inferior hypertrophica (so-called), etiology (Baurowicz: abstract) . . . . , .

Chromic acid solution in the treatiment of malignant tumours of mucous membrane of pharynx, nose, and larynx (Hamon de Fougeray)

Crechomskr, on a syphilitic tumour of the tonsil simulating malignant neoplasm (abstract) .

CIEglewrez, the therapeutic action of ichthyol in catarrhal inflammation of the mucous membrane of the larynx (abstract). .

Cuark (J. Payson), cyst of the larynx

"Cleavage" of the middle turbinate (so-called), simulated by case of chronic ethmoiditis ( $\mathrm{H}$. Tilley)

Clinical examination of genuine acute exudative middle ear inflammation (Nadoleczny : abstract) studies in complications of acute and chronic midille-ear suppuration (Leutert-Konigsberg : abstract)

CoBbetr (Louis), diphtheria in the horse (abstract) . . .

Cocaine : economy in employment of (W. Wingrave)
Cochlea, sequestration, in cured case of cerebellar abscess (E. B. Waggett)

Cochlea, sequestration, in cured case of cerebellar abscess ( $\mathrm{E}$. B. Waggett)
Coin, small silver, lodged in larynx for four weeks; removal with forceps under cocaine (Walker Downie : abstract)

Coue, some observations on the anatomy and physiology of the ear (abstract). 
Collier (H. Stansfield) and SpICER (R. H. Scanes), sarcoma of the carotid sheath; removal of the growth, together with portions of the carotid arteries, internal jugular vein and pneumogastric nerve: recovery (abstract) .

Collier (Mayo), case of complete abductor paralysis of the left vocal cord

Commissure, anterior, pseudo-membranous adhesion in (Sir Felix Semon)

CoMpaIRED, perforating ulcer of the mouth (abstract)

Congenital laryngeal obstruction (C. H. McIlraith : abstract) cleft palate in a man aged twenty-eight (D. Vinrace)

Conjunctiva, chronic pemphigus of (Otto : abstract)

CONNELL (J.C.), the cure of stammering and stuttering (abstract)

Consanguineous marriage: see Marriage (consanguineous).

Cordes (Hermann), the treatment of the diseases of the sphenoidal sinus (abstract) .

Coryza: importance of auto-intoxication in periodic and aperiodic coryza (Dr. Mounier)

Cough, hysterical (Bournoville : abstract) $\quad \cdot \quad \cdot \quad \cdot \quad \cdot$ treatment, particularly in laryngeal tuberculosis (W. Freudenthal: abstract)

Coughing, violent, causing anomalous central hæmorrhage (P. Macleod Yearsley)

Conval (Dr. J. G.), appointed Lecturer on Aural Surgery in Anderson's Medical College, Glasgow . . . .

CountaDe, detection of simulated unilateral deafness by a deep-toned fork

- modifications of the counter-pressure tongue-depressor . nasal and aural speculum-holder

two cases of accidental cauterization of the larynx by caustic

poisons
hysterical deaf-mutism in little girl aged three and a half
on the compression of the trachea by an aneurism of the arch of the aorta simulating paralysis of the abductors (abstract)

palliative treatment of cancer of the trachea and larynx, use of rubber catheter as tracheal cannula

Cousteau, pulmonary emphysema due to experimental nasal obstruction .

Cox (Robinson), Graves' disease, with report of the successful treatment of a case (abstract)

Cozzrtrino on bacteriological and histological study of ozæna (abstract)

CREel (M. P.), on treatment of recurrent attacks of spasmodic croup (abstract) .

Creosote, carbonate of, in injections for fotid breath (Bayer: abstract)

Cricoid cartilage, ecchondroma of (Lenzmann : abstract)

Croup, recurrent spasmodic treatment (M. P. Creel : abstract) .

Crowfoot (Dr.), discussion on the pathological distribution of the diphtheria bacillus and the bacteriological diagnosis of diphtheria

Crusts in cases of chronic purulent nasal discharges (E. W. Roughton) :

Cumberbatch (A. E.), on selection of suitable cases for the complete mastoid operation for the cure of chronic suppurative disease of the middle ear

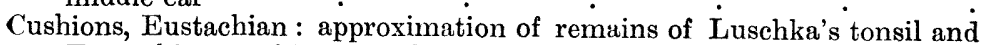
Eustachian cushions producing recesses in naso-pharynx (StClair Thomson).

Cut-throat: see Throat.

Curtain-ring exhibited, removed from pharynx of a child (H. L. Lack) 379 for eight years in pharynx of child (H. L. Lack: abstract) $\quad . \quad 676$

CuRTrs (Holbrook), discussion on intra-nasal treatment of ear-disease $\quad . \quad 487$

CUvellier (H.), hypertrophy of the tonsils and adenoid vegetations $\quad . \quad 593$

Cyst at base of tongue in child aged three (H. FitzGerald Powell) $\quad . \quad 437$ (bony) of middle turbinate bone (H. Tilley) $\quad . \quad \cdot \quad 437$ cystic degeneration of the mucous membrane of the nose and accessory sinuses (Fr. Schlagenhaufer: abstract) 
Cyst (dental): dental cysts of superior maxilla (P. Jacques and G.

Michel : abstract)

dentiferous of superior maxilla (P Berger: abstract)

of epiglottis (H. D. Hamilton : abstract) . $\quad . \quad 52$

- lantern demonstration (IV. Jobson Horne) . . 147

of floor of the external auditory meatus (Dr. Ephraim : abstract) . 220

of the larynx (J. P. Clark) . . . . 309

- probably cystic nature of new growth in vocal cord (J. Dundas

Grant) . $\quad \cdot \quad \cdot \quad 41$

serous, of the auricle (Guranowski : abstract) . . 402

suppurative, of turbinal bone (H. A. Davis) . . 260

- of the tonsils (Mounier : abstract) . $\quad$. $\quad$. $\quad$. 211

Dalby (Sir William), Presidential Address at meeting of Otological Society

of United Kingdom chic purulent otorrhcea suitable for the mastoid

operation $\cdot$.

DALY, Mrs. A. C. (of Pittsburg), obituary notice · . . 63

DANA (Charles L.), the common forms of meningitis and their recognition, with special reference to serous meningitis (abstract) $\quad . \quad$. 342

Davis (Henry J.), case of suppurative cyst of turbinal bone $\quad \cdot \quad . \quad 260$

boy case of extreme hypertrophy of inferior turbinals in a case of enlargement of lingual tonsils in a woman aged thirty, with secondary syphilis .

- case of ulceration of larynx (shown for Mr. S. Paget) _ 393

Deaf-mutes, acoustic exercises for (V. Urbantschitsch, and Dr. Schwendt) 558,560

Deaf-mutism and consanguineous marriage (A. H. Huth : abstract) $\quad 446$

hysterical, in little girl aged three and a half (Courtade) (D. Roy:
Deafness, catarrhal, so - called, prognosis and treatment (D. Roy abstract) . .0 .673

- complete, following railway accident (collision) (Pollak : abstract) . 112

- due to tumour of medulla and pons (A. A. Gray) . $\quad 29$

- hysterical (Lannois et le Mare Hadour: abstract) . $\quad .450$ cured by suggestion (Taptas : abstract) . . 454

- in right ear for twelve months, occurring in case of discharge of pus and blood from naso-pharynx for over twelve months (Barclay Baron)

- - simulated unilateral, detection by deep-toned fork (Courtade)

$\begin{array}{lll}\text { DE BLOIS (T. A.) on fractures of the nose } & \cdot & 298 \\ \text { DECKER (Alfred), on the operation for adenoid vegetations (abstract) } & \cdot & 208\end{array}$

Decortication of the face (Dr. Goris) . . . . 606

Deflections of the cartilaginous septum, Asch's operation for (Thorner: abstract) . . . . 510

- of the septum, treatment (E. J. Moure) . . . . 598

Degeneration, cystic, of the mucous membrane of the nose and accessory sinuses (F. Schlagenhaufer : abstract) . . . . 335

DE GUY on hæmatemesis in diphtheria (abstract) . . . . 327

DELAGÉNIÈRE on tracheotomy in bucco-pharyngeal operations (abstract) ; 337

Delavan (D. Bryson) on methods of treatment and the statistical results a consideration of the statistics of the operations for the relief of malignant disease of the larynx $\quad \cdot \quad \cdot \quad \cdot 645$

DeLIE, considerations on the operative treatment of fibrous naso-pharyngeal

polypi (abstract)
Desstanche, Professor, committee for organizing manifestation in his

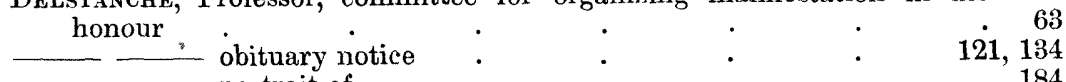

Delstanche (jun.) on importance of ophthalmoscopic examination in purulent affections of the ear (abstract) . $\quad \cdot \quad 206$

Dench (E. B.), synechiotomy of the stapes for improving the hearing in $\begin{array}{lll}\text { chronic suppurative otitis media residua (abstract) } & . & 107\end{array}$ 
Dentiferous cyst of superior maxilla (P. Berger: abstract)

Dentistry, application of dental instruments to nasal surgery (Dr. Suarez de Mendoza)

Deviations of nasal septum, correction of (John O. Roe)

Diagnosis, bacteriological, of diphtheria (discussion opened by F. W.

Andrewes, British Medical Association) .

cases for: boy aged ten suffering from aphonia (E. W. Roughton)
extensive ulceration of throat (R. H. Scanes Spicer)

\begin{tabular}{lr}
- cases for: boy aged ten suffering from aphonia (E. W. Roughton) \\
\hline extensive ulceration of throat (R. H. Scanes Spicer) \\
\hline growth or granuloma of epiglottis (E. B. Waggett)
\end{tabular}

- laryngeal affection in tubercular patient (G. C. Cathcart) : 201

- laryngeal case (R. H. Scanes Spicer). . . . 373

- nasal case (Atwood Thorne). . . . . $\quad 35$

- ulceration of pharynx (StClair Thomson) $\quad: \quad .204$

— ear diseases, by Gellé's test (Dr. Bing : abstract) . . 342

mistake in (Sir F. Semon). $\quad . \quad 71$

naked eye, in cancer of larynx (J. N. Mackenzie) : $\quad .524$

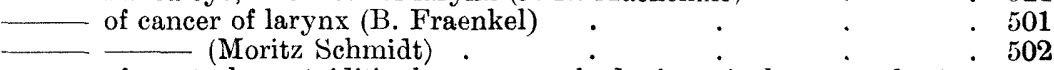

- of central mastoiditis by new method of auricular auscultation

(Ostino : abstract) . $. \quad . \quad . \quad . \quad .344$

- of œesophageal stenosis (G. Holzknecht : abstract) $\quad \cdot \quad+675$

special methods in cases of chronic purulent nasal discharges 'atge.

(E. W. Roughton) . . . . . 242

Didsbury, voluminous tumours of the base of the tongue obstructing larynx . . . . . . . . 287

Drckerman (Edward T.), papillomata of the larynx in children (abstract) . 668

Dievlafoy on cerebellar abscess (abstract) ..$\quad 567$

Digestion: digestive disorders associated with chronic rhino-pharyngitis and tonsillitis (E. C. Aviragnet)

Dioniso, method of augmenting the efficacy of catheterization and of facilitating the injection of liquids into the middle ear (abstract) . 56

$\begin{array}{ccc}\text { Diphtheria, abstracts of literature on } & . & 94,287,327,394,439,614 \\ \text { antitoxin serums . } & . & .\end{array}$

- bacillus: pathological distribution (discussion opened by F. W.

Andrewes, British Medical Association) .

bacteriological diagnosis (discussion opened by F. W. Andrewes,

British Medical Association) .

- case of membranous angina and membranous vaginitis of doubt-

fully diphtheritic nature occurring in patient convalescing from scarlet

fever (Millard: abstract) angina with fusiform bacilli and the spirillæ of Vincent (J. Freyche: abstract) differential diagnosis from so-called ulcerous angina (Raczynski : abstract) . . . . . in connection with adenoid vegetations (Plottier : abstract)

laryngeal, extensive mediastinal emphysema in fatal case (W. Ewart

and H. B. Roderick : abstract)

paralysis in : see Paralysis (diphtheritic).

pharyngeal and naso-pharyngeal, with multiple abscesses of tonsils

and empyemata of Highmore's antra (Sendziak : abstract) $\quad 327$

serum treatment (Schmidt, Siegel : abstract) . $\quad .287$

- strength and preservation of antitoxin (Tavel : abstract) ${ }^{\circ} \quad .287$

of vulva (E. E. Ware : abstract) . $\quad . \quad$. $\quad . \quad 439$

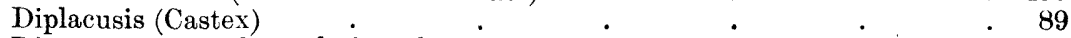

Diseases, general: relation between empyema and general diseases (Lapalle)

Distension of maxillary antrum (H. Lambert Lack) · $\quad \cdot \quad \cdot 92$

Dog-nose: see "Henpuye," • • • 436

DoNoGaNY on the function of the false cords in phonation (abstract) $\quad .100$

DorNer, case of sarcoma of the tongue (abstract) . $\quad . \quad 328$ 
Douche, nasal, and its substitute (Neumann : abstract)

Downie (Walker), a case in which a small silver coin was lodged in the larynx for four weeks; removal with forceps under cocaine (abstract)

a case of primary sarcoma of the tonsil in a woman aged fifty-

eight: successful extirpation through the mouth .

DRABCZYK on electrolysis and its application in nasal diseases (abstract) .

Duct (fronto-nasal), stenosis, causing painful recurrent catarrh of frontal sinus (Dr. Luc) thyroglossal: see Thyroglossal duct. thyroid: see Thyroid duct.

Duplication of external auditory meatus (Guranowski : abstract)

Dura mater (venous sinuses), radiographical researches on topographical relations to walls of skull (P. Regnier and J. Glover : abstract) .

DUvivier, cancer of the larynx (abstract)

Dysphagia : treatment, particularly in laryngeal tuberculosis (IV. Freuden-

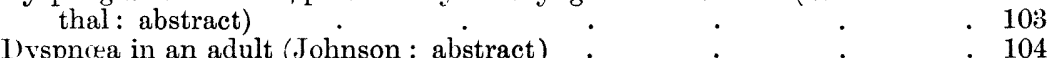

$\stackrel{0}{-}$ of two years' duration in a girl aged three and a half (E. Ausset: abstract)

Ear, abstracts of literature on $\quad$. $\quad 56,107,223,342,402,445,567,618,672$

Ear, abstracts of literature on acte leucocythæmic affections of ear ; case of acute Ménière's symptoms in spleno-medullary leucocyth:emia

(F. P. Weber, with pathological report by R. Lake) anatomy and physiology (Cole : abstract) $\quad \cdot \quad$. $\quad$. 56 auditory nerve, central connections (W. A. Turner) $\quad \cdot \quad 131$ aural complications of ozæna (P. Lacroix) $\quad . \quad+134$ - reflexes in an hysterical patient (Ricard : abstract) . 454 auricular origin of retropharyngeal abscess (Urbano Melzi) . 25

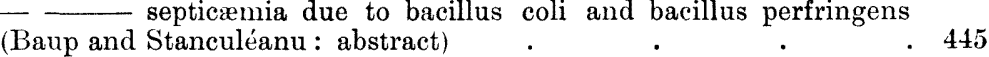

- case of chronic middle-ear suppuration (Arthur Cheatle) $\quad$. $\quad 316$

cases of facial neuralgia of aural origin (Sarremone) . $\quad . \quad 286$

- diagnosis and treatment of otitic pyæmia (J. Dundas Grant) 513

- (diseases), certain affections of ear: observations on recognition of aural diseases in medical practice (C. A. Ballance : review) 172

- diagnosis by Gellé's test (Dr. Bing: abstract) . . . 342

- discussion on intra-nasal treatment (opened by P. McBride, \begin{tabular}{rr} 
p. 471 ; E. Cresswell Baber, p. 476 ; J. Dundas Grant, p. 479) & 471.491 \\
\hline
\end{tabular}

pneumatic treatment (G. Nuvoli) . . . 70

dry chronic catarrh of middle ear, in connection with subperiosteal

abscess over base of mastoid process (Dr. Hasslauer : abstract) . 403

- early suture of retro-auricular incision after mastoid operation

(Botey : abstract) . $\quad . \quad$. $\quad . \quad 342$ - effect of artillery practice on the ears (R. Miuller : abstract) $\quad$. 228 eczema, treatment (M. I.ermoyez: abstract) . . . 450 - exostoses (W. H. Kelson) • $\quad . \quad \ldots \quad . \quad 666$

- experiments in anæsthesia of the semilunar canals of the ear

(G. Gaglio) $\quad . \quad 5 \quad . \quad 5 \quad . \quad 532$ $\stackrel{-}{-}$ on anæsthesia of semicircular canals ( $\dot{G}$. Gaglio) $\quad 569$ foreign body, removal (J. G. Macaskie: abstract) . . $\quad 673$ - Gellé's test, prognostic value (Max Breitung: abstract) . . . . 446

- importance of ophthalmoscopic examination in purulent affections

of (Delstanche, jun.: abstract)

- increased pressure; connection with anomalous case of central hæmorrhage due to violent coughing (P. Macleod Yearsley) - internal, disorders of ; Sajous's cyclopædia of practical medicine

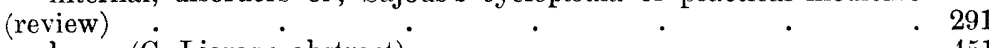

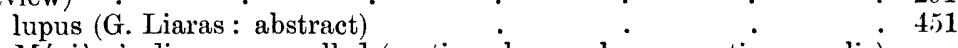
- Ménière's disease, so-called (vertigo ab aure læsa; vertigo auralis) (Oppenheim : abstract) 
Ear (middle) : acute tuberculosis (Gaudier : abstract) . . . $\quad 57$

tion chronic suppuration and thrombosis of lateral sinus; operation ; recovery (A. Cheatle) . ${ }^{\circ} \cdot{ }^{\circ}$.

(W. Milligan) (W. Mronic suppuration treated by antiseptic purification of meatus and adjacent parts (U. Pritchard) . . 123, disease: recent progress in treatment of some dangerous complications (Milligan : abstract)

- inflammation: see Otitis media. method of catheterization (Dioniso : abstract)
pathology and pathological anatomy (H. Haiké : abstract)
purulent inflammation of middle ear leading to thrombosis
of lateral sinus cured by opening of sinus and ligature of internal
jugular vein (T. Barr and J.H. Nicoll : abstract).

studies in complicationte and chronic; bacteriological and clinical complications of (Leutert-Konigsberg : abstract) $\cdot$; internal jugular vein not ligatured: recovery (A. H. Cheatle: abstract) . nasal and aural speculum holder (Courtade) . new method of auricular auscultation in diagnosis of central mastoiditis (Ostino: abstract).

noises in, due to spasmodic contraction of tensor tympani or of dilators of Eustachian tube (Mouret: abstract) otitic origin of abscess of occipital part of brain (Heiman : abstract)

thrombo-phlebitis of left sigmoid sinus followed by exten-

sive transference of thrombotic material in retrograde direction (Biehl: abstract)

otitis media neonatorum (L. Aschoff: abstract) auricle and whole of meatus had been removed for adeno-carcinoma (A. Cheatle) production of local anæsthesia in (A. A. Gray: abstract)
reciprocal influence of affected upon normal ear (Ouspenski : abstract). report of seventy-seven radical operations $(\dot{P}$. Manasse and $\dot{A}$. Wintermantel : abstract)

sarcoma growing from middle ear of a boy of five (Dr. Alt: abstract) . - selection of suitable cases for the complete mastoid operation for the cure of chronic suppurative disease of the middle ear (A. E. Cumberbatch)

statistics of the dangerous complications of suppurative ear diseases and of operations on the mastoid process (M. Teichmann : abstract) . suppuration, acute purulent, special danger in elderly people ( $B$. Heine : abstract) surgical treatment of aural stenosis (F. Siebenmann and Ricardo Botey)

testing the hearing with high and low notes in diseases of the ear

(A. A. Gray : abstract)

- - thrombosis, septic, of lateral and longitudinal sinuses, with pus in intact middle ear (W. Jobson Horne) year-book (G. P. Head and A. H. Andrews : review) $\quad \cdot{ }^{\prime} \quad$.
see also Tympanum.

Earache: gelato-glycerine bougies in treatment of (Richards : abstract) .

EARLE (Edward R. C.), two cases of cut throat, with opening of the airpassage (abstract)

Fcchondroma of the cricoid cartilage (Lenzmann : abstract)

Eclampsia due to paracentesis ( $H$. Obraszoff : abstract)

Economy in employment of cocaine (W. Wingrave) 


\section{Index.}

Eczema of ear, treatment (M. Lermoyez : abstract)

EGGER, foreign body (pin) in the larynx $\quad . \quad$. $\quad . \quad 91$

Electric snare (new) for removal of adenoids (Garel : abstract) . 48

Electricity (therapeutical) in treatment of exophthalmic goitre (Valude: abstract) - transformation of alternating into constant current: installation of silent motor (Piaget : abstract) cannula sixteen years (M. Boulay and J. Boulai).

palpation of maxillary antrum and endo-nasal operation for (Dr. Kaspariant) . treatment (E. W. Roughton). empyemata of both antra of Highmore in diphtheria of pharynx and naso-pharynx (Sendziak : abstract).

- frequency of, in nasal accessory sinuses, disproportionate in living and dead (Lichtwitz: abstract) of frontal sinus (Hegetschweiler : abstract) (Rogers : abstract) chronic (H. Tilley : abstract)

(H. Tilley). two cases presenting features of unusual interest cured by radical external operation (H. Tilley)

(H. Tilley) . cured by radical external operation ( $\mathrm{H}$. Tilley)
and antrum, double, with great distension of bridge of nose and ethmoid cells causing exophthalmos (Büler and Byers: abstract) radical operation (H. Tilley) . six cases (H. Tilley) with orbital abscess; operation and cure (Martin : abstract) of mastoid antrum (Dr. Bloch : abstract) mediastinal: early and late varieties in fatal case of laryngeal diphtheria after tracheotomy (W. Ewart and H. B. Roderick: abstract) extensive, in fatal case of laryngeal diphtheria (IV. Ewart and H. B. Roderick : abstract)

- of orbital wall of anterior ethmoidal cells caused by blowing nose

(J. Dundas Grant) . . pulmonary, due to experimental nasal obstruction (Cousteau) $\quad$. 60 - relation between emprema and general diseases (Lapalle)

subcutaneous, secondary to laryngeal perforation in phthisical patient (Raviart: abstract)

Endo-nasal operation for antral empyema (Dr. Kaspariant)

Endothelium: case of endothelial fibro-angioma of external auricular meatus (Urbano Melzi)

Enlargement of nose (William Hill)

- (StClair Thomson)

- lateral (William Hill) of lingual tonsils in case of secondary syphilis (H. J. Davis)

EPHRAIM (Dr.), threatening swelling of a tumour of the larynx from pregnancy and labour (abstract)

- on degenerated adenoids in a woman of sixty-seven (abstract) . 
Epileptic suffering from mastoid disease, acute otitis media, and pyæmia, result of injury (R. A. Wilson: abstract)

Epistaxis from the ethmoidal veins (A. Brown Kelly).

Epithelioma of left ary-epiglottic fold (Wyatt Wingrave) removed nine years previously (L. Browne)

- use of epithelial grafts in healing bone-cavity left by mastoid operation (Charles A. 13allance)

Erythema, unusual erythematous eruption associated with membranous angina and membranous vaginitis in patient convalescing from searlet fever (C. K. Nillard: abstract)

Escat on intubation without permanent supervision: "tubage sans surveillance permanente" (abstract) . . laryngeal arthritis

Eschar, pharyngo-œesophageal, caused by ingestion of hydroct (Le Gendre: abstract)

EschweIler, case of fibro-myxoma of the mastoid process (abstract)

Ethmoid, bony spur from (R. Lake) Roughton)
see Cells (ethmoidal). see Veins (ethmoidal).

Ethmoiditis, chronic, simulating so-called " cleavage " of middle turbinate (H. Tilley) purulent (Dr. Hajek)

- - treatment (F. H. Bosworth) . . 504

Etiology, obscure, in case of thrombosis of lateral sinus (S. Lodge, jun.) * 493

Eulenstein (H.), percussion of the mastoid process (abstract) . . 402

Eustachian cushions : see Cushions (Eustachian).

EWART (W.) and RoDerick (H. B.), extensive mediastinal emphysema in a fatal case of laryngeal diphtheria, with remarks on the early and the late variety of emphysema observed in the case after tracheotomy (abstract) .

Exophthalmos from empyema of frontal sinus and ethmoid cells; operation; recovery (Buller and Byers : abstract)

Exostoses, aural (W. H. Kelson) . $\quad . \quad$.

Extract, suprarenal, use followed by secondary hæmorrhage (F. E. Hopkins)

Eyeball, abscess, with frontal sinus empyema (Martin : abstract)

Face, case of obstructed subdermal lymphatics of the face in which frontal and antral disease had been suspected (P. de Santi) . - cases of facial neuralgia of aural origin (Sarremone) - decortication (Dr. Goris). surgery of sinuses of face in relation to surgery of orbit (G. Laurens)

FAGGE (C. H.), case of healing after ossiculectoiny

Faraci (G.), on the possibility of reopening the fenestra ovalis in cases of osseous anchylosis of the stapedo-vestibular articulation (tyridianoixi ovalis)

FarLow (J. W.), case of ozana of probable sphenoidal origin $\quad \cdot \quad \cdot \quad \cdot \quad \cdot 309$

Fauces, lupus of (Wyatt Wingrave) $\quad . \quad 162$

Faucitis, recurring membranous, due to bacillus of Friedlander : report of

case (Emil Mayer) baure (Maurice), a fatal case of Graves' disease with co-existing
Faure myxœedema (abstract)

FEER, on bromoform treatment of whooping-cough (abstract) $\dot{ }$. acid (abstract) 


\section{Index.}

Fenestra ovalis, possibility of reopening in cases of osscous anchylosis of the stapedo-vestibulur articulation (G. Faraci)

Fever, scarlet: see Scarlet fever.

\section{typhoid: see Typhoid fever.}

Fibro-angioma, endothelial, of external auricular meatus (Crbano Melzi). Fibroma of the larynx (A. B. Thrasher)

Fibro-myxoma of mastoid process (Eschweiler: abstract)

of post-nasal region: case after removal (H. FitzGerald Powell) :

Fibro-papilloma of vocal cord : restoration of voice after incomplete removal (J. Dundas Grant)

Fibro-sarcoma of nose with unusual course (Siendziak: abstract)

Fixation, complete, of left vocal cord (Wyatt Wingrave)

FLATAU (T. S.), radical operation on bony occlusion of the choanæ (abstract) on radical operation of the osseous atresia of the choana (abstract)

- on disturbances of intonation and loss of voice: contribution to the doctrine of disturbances of the voice of singers (abstract)

Fluid (cerebro-spinal) : see Cerebro-spinal fluid.

Forceps, new universal laryngeal (P. Watson Williams)

Foreign body in bronchus; removal without operation (Schrötter : abstract) - in cases of chronic purulent nasal discharges (E. W. Roughton) in meatus, extracted by opening of mastoid (Dr. Kaufmann)

- migratory, with X-ray illustrations (D. Bradon Kyle)

Fork, deep-toned, in detection of simulated unilateral deafness (Courtade)

Formol, in treatment of acute and chronic suppurative otitis (Vacher: abstract)

Fossa, tonsillar, sarcoma of, simulating phlegmon of that region (Gaudier:

abstract)
Fracture of larynx, direct : stenosis, dilatation, cure (Boulai)

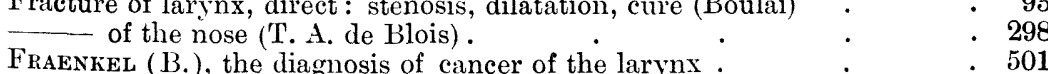

France: geographical distribution of goitre in (Poncet: abstract) $\quad .512$

FreUdenthaL (W.), the treatment of cough and dysphagia, particularly in

laryngeal tuberculosis (abstract)
FREYCHE (J.), clinical and bacteriological study on diphtheritic and ulcerous
angina with fusiform bacilli and the spirilly of Vincent (abstract) angina with fusiform bacilli and the spirillæ of Vincent (abstract) $\quad 327$

Friedlander's bacillus: see Bacillus of Friedlander.

Frontal sinus: see Sinus, frontal.

Frost-bite of auricle (Professor Grïbner)
Fullerton ( $\mathrm{k}$ ), certain cases of otitis media acuta, in which it is important to make early paracentesis of tympanic membrane (abstract).

Frret (F.) frontal sinus transilluminator

and Barbon (Lubet), on study of fronto-maxillary sinusitis (abstract)

Gacilio (Professor G.), experiments of anæsthesia of the semilunar canals of the ear (translated by Nacleod Yearsley)

- experiments on anesthesia of the semicircular canals of the ear (translated by Macleod Yearsley)

Galvano-cautery, use in laryngeal tuberculosis (Schmithuisen : abstract) .

GAREL, new electric snare for the removal of adenoids (abstract)

- on stereoscopic photography of larynx (abstract)

Gas contained in tumour in neck (Guinard : abstract)

GaUDIER, sarcoma of the tonsillar fossa simulating phlegmon of that region (abstract).

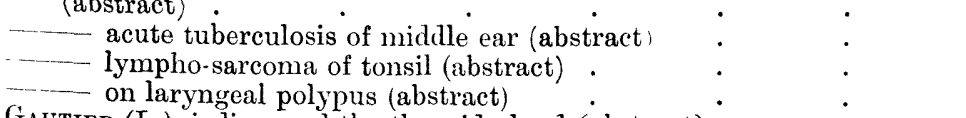

GaUTIER (L.), iodine and the thyroid gland (abstract) $\dot{ }:$

Gelato-glycerine bougies, use in treatment of earuche (Richards: abstract) prognostic value (Max Breitung: abstract) 
Geographical distribution of goitre in France (Poncet : abstract) . $\quad \begin{array}{r}\text { PAtit } \\ 512\end{array}$

GERRAD (P. N.), otitis externa tropica (abstract) . $\quad . \quad 109$

GIBB (Joseph S.), unusual papillomatous growth in the larynx (abstract) . 669

GibB (Wishart), removal of septal spurs : a note upon the use of CarmaltJones's spokeshave (abstract) .

Gland, thyroid: see Thyroid gland.

Glands, cervical, rapid enlargement in elderly woman (J. Dundas Grant) .

Glandular form of cancer of pharynx, so-called (A. Poncet and Birard: abstract)

Glottis: œedema: lantern demonstration (W. Jobson Horne)
GLover (Jules), on the presence of the short variety of Lïfler's bacillus in

Grover (Jules), on the presence of the short variety of Lïfller's bacillus in
the exudate of ulcero- or eroso-membranous tonsillitis following operation (abstract) .

and Regnier (Paul), radiographical researches on the topographical relations of the brain, the frontal and maxillary sinuses, and the venous sinuses of the dura mater to the walls of the skull (abstract) .

GLuck, modern laryngeal surgery

Glycerine: see Gelato-glycerine.

Goitre, exophthalmic, electric treatment (Valude : abstract)

- geographical distribution in France (Poncet; abstract) .

(simple) treatment in young adults (Murray : abstract) .

Goldsurth (P. G.), chronic suppuration of right maxillary antrum and anterior ethmoidal cells (abstract)

Gomperz (Dr.), a temporal bone from case of leukiemia notes on new remedies; argonin and orthoform

GOoDALL, pathological histology of acute tonsillitis (abstract)

Goris (Dr.), the immediate and remote effects of thyrotomy decortication of the face

DE Gorsse on an anomaly of the soft palate (abstract)

Gouguenhem and Lombard (E.), indications for operation in cancer of the larynx

GouLD's year-book, 1900 (surgery) (review) $\cdot \dot{\cdot}$ GRADLE, odema of the nasal mucous membrane and redematous occlusion of the nasal passages (abstract)

Grafts : epithelial grafting of labyrinth (Charles A. Ballance) .

- - see also Epithelium.

Grant (J. Dundas), a case of new growth in the vocal cord, probably cystic in nature.

- a case of fibro-papilloma of the vocal cord causing hoarseness; restoration of voice after incomplete removal of the growth .

- case of tuberculous ulceration of the pharynx and of the lower lip. - a case of thrombo-phlebitis of the lateral sinus treated by operation without ligature of the internal jugular vein; recovery. case of emphysema of the orbital wall of the anterior ethmoidal cells, caused by blowing the nose case of bridge-like synechis between the septum and inferior turbinated body - case of hoarseness from laryngitis, secondary to rhinitis in a chaffcutter case of perforation healed by trichloracetic acid

case of inter- and sub-cordal growth, with hoarseness of sudden development - abstract of and comments on cases of dangerous sequelæ of suppurative otitis media occurring in Professor Schwartze's Otological Clinic, published by Drs. Grunert and Zeroni 
GRANT (J. Dundas) : female patient, aged forty-nine, from whom the larynx

had been completely removed on account of sarcoma.$\quad .432$

- case of tonsillar ulceration of uncertain origin (? specific) $\quad .433$

- case of intercordal tumour (tubercular) of the larynx in an elderly

opening of a discussion on intra-nasal treatment in ear disease

practical points in the diagnosis and treatment of otitic pyæmia

(abstract).

- case of nasal synechia $\quad$. $\quad . \quad$.

case of rapid enlargement of cervical glands in an elderly woman and THoRne (Atwood), retrospect of otology

Granuloma or growth of epiglottis for diagnosis (E. B. Waggett)

Graves' disease: administration of bile in treatment of (C. M. Allan : abstract)

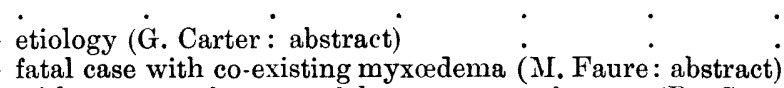
with report of successful treatment of case (R. Cox: abstract) .

GraY (Albert A.), a case of tumour of the medulla and pons, causing deafness and other remarkable symptoms. - on testing the hearing with high and low notes in diseases of the ear (abstract) the production of local anæsthesia in the ear (abstract) .

GRossaRD, tubercular perforation of the palate (abstract)

Growth from arytænoid region in male aged fifty-six (R. Lake) . $\quad$. 257 in larynx (W. H. Kelson) .

\section{of male aged twenty-five (H. Fitzgerald Powell)} thirty-five years (Hector Mackenzie) . abstract) benign, causing pulmonary lesion (P. de Champeaux

- in neck associated with odema of one ary-epiglottic fold $(\dot{J}$. Dundas Grant) in right lobe of thyroid gland (Dr. Tresilian) $\cdot$
in vocal cord, probably cystic (J. Dundas Grant)
inter- and sub-cordal, with hoarseness of sudden development
J. Dundas Grant) .

(J. Dundas Grant) (? lymphangioma) removed from right ventricular band of man

aged forty (E. Furniss Potter). $\quad$. $\quad$. $\quad$. $\quad 34$ new (C. Nourse) . $\quad . \quad$. $\quad . \quad 6 \quad$. $\quad 662$

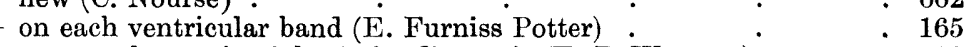

- or granuloma of epiglottis for diagnosis (E. B. Waggett) . $\quad 82$

pharyngeal and laryngeal with microscopic section (E. Furniss Potter)

Potter) involving larynx in case of man aged fifty-nine $(\dot{E}$. Furniss . • • • • . . . . 258 post-nasal, considered persistence of adenoids (E. Furniss Potter) . 164

removal of post-nasal growths; question of following complications

(Sendziak : abstract)

- removed from meatus of elderly ${ }_{-} \cdot{ }^{\circ} \quad \cdot \quad 397$

- see also Malignant growth.

Gruber (Professor), on the pathology of relaxation of the membrana tympani (abstract) .

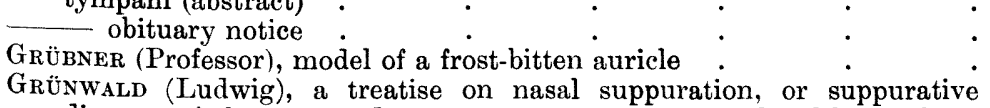
diseases of the nose and its accessory sinuses (translated by William Lamb) (review)

Grunert and Zeroni, cases of dangerous sequelæe of suppurative otitis 
media occurring in Professor Schwartze's Otological Clinic in the

University of Halle during the last two years . $\quad . \quad 409$

Guaiacum resin ; preparation in " tabloid " form $\quad . \quad 5 \quad . \quad 50$

GUINARD, tumour containing gas in neck (abstract) $\quad \cdot \quad \cdot \quad \cdot \quad \cdot 446$

Gums : surgical treatment of gingivitis (Buisseret : abstract) $\quad \cdot \quad \cdot 328$

GURANOWSKI, case of duplicated external auditory meatus (abstract) $\quad .402$

- on a serous cyst of the auricle (abstract) . $\quad . \quad 5402$

Hæmatemesis in diphtheria (De Guy : abstract) . . . . 327 Hæmophilia: operation on pharyngeal tonsil in subject of hæmophilia ;
death (R. Sachs)

Hæmoptysis: see Pseudo-homoptysis.

Hæmorrhage, central, connected with increased pressure in ear, due to violent coughing (P. Macleod Y'earsley).

- following adenoid operations (Martin. abstract)

. $\quad .49$

- secondary, after use of suprarenal extract (F. E. Hopkins) _ $\quad .313$

spontaneous, from septum (Natier : abstract) . 597

HAIKE (H.), contribution to the pathology and pathological anatomy of the middle ear and labyrinth (abstract) $. \quad . \quad 672$

Hajek (M.), Pathologie und Therapie der entziindlichen Erkrankungen der Nebenhöhlen der Nase (pathology and treatment of inflam. matory affections of the accessory sinuses of the nose) (review) . 115

- purulent ethmoiditis . . . 503

HaMiLton (H. D.), cyst of the epiglottis (abstract) : $\quad \cdot \quad \cdot 503$

HaMMerschlag, spontaneous cure of otitis media (abstract) $\quad \cdot \quad \cdot 109$

HANON DE Fougerterical deafness in a man of thirty-nine (abstract) . 228 of malignant tumours of the mucous membrane of pharrnx, nose, and larynx

HANSBERG, two cases (one cured) of cerebellar abscess due to otitis (abstract)

Hare-lip : deep median furrow of lower lip and chin, median division of inferior maxilla, and malformation of tongue (P. Redard and Frank Michel : abstract)

Hartmann (Arthur), the anatomy of the frontal sinus and the anterior ethmoidal cells

Harveian Society of London, proceedings
on a universal system of acoumetry

Haslauer (Ur.), a case of large subperiosteal abscess over the base of the mastoid process arising in connection with chronic dry catarrh of the middle ear (abstract)

Head (G. P.) and ANDrews (Albert H.), the year-book of the nose, throat, and ear (review)

Hearing : auditory results of removal of post-nasal adenoids (D. McKeown) - synechiotomy of stapes for improving hearing in chronic suppura. tive otitis media residua (E. B. Dench : abstract). abstract) with high and low notes in diseases of the ear (A. A. Gray: testing of: see Acoumetry. Heart : vitia cordis causing changes in upper air-passages (Sokolowski :
abstract)

Heath (Charles), case of sinuses in the vault of naso-pharynx $: \quad \cdot \quad 341$

HEGETSCHWEILER, on empyema of frontal sinus (abstract)

Heiman, case of abscess of the occipital part of the brain of otitic origin (abstract) . .402

HEINDL, on treatment of rhinoscleroma or seleroma (abstract) : $\quad .402$

Heine (B.), the special danger of acute purulent ear suppuration in elderly
people (abstract)

Hellat (P.), tonsillitis streptothricia $\quad \cdot \quad \cdot \quad \cdot \quad 672$

- psychic salivation . . . . 596

HELLET, . . . . . 608

Hemiatrophy of the • • 667

Hemiatrophy of the tongue (L. A. Parry : abstract) : $\quad{ }^{-} \quad \cdot 616$

HENke, entire absence of the urula (abstract) $\quad . \quad{ }^{2} \quad .104$ 


\section{Index.}

Hennebert on cavernous angioma of the external auditory meatus (abstract) .

"Henpuye" (dog-nose) in Gold Coast Colony (A. J. Chalmers : abstract).

Hessler (B.), middle-ear suppuration and brain tumours (abstract) .

Heymann's handbook of laryngology and rhinology, parts 21-23 (review) .

Hiccup, a reflex of adenoids (Thomas : abstract) . . . 39

HrLl (G. William), case of enlargement of the nose $\quad . \quad$. $\quad$. 34 a case of lateral enlargement of the nose . . $\quad 34$

a case of stammering in a young man (shown by Atwood Thorne) . 165)

Histology, pathological, of acute tonsillitis (Goodall : abstract) . .96

Hoarseness and aphonia of long standing in a girl aged thirteen (P. de Santi) 264 caused by fibro-papilloma of vocal cord (J. Dundas Grant) $\quad . \quad 42$

from laryngitis secondary to rhinitis in a chaff-cutter (J. Dundas Grant) of remarkably sudden development in case of inter-and sub-cordal growth (J. Dundas Grant)

Holzknecht (G.), the diagnosis of osophageal stenosis (abstract)

Hopkins (F. E.), on secondary hrmorrhage after use of suprarenal extract

Hopman, on a case of rhinoliths on both sides (abstract)
Horne (W. Jobson), lantern demonstrations (1) codema of the glottis,

Horne (W. Jobson), lantern demonstrations (1) cdema of the glottis,
(2) cyst of the epiglottis, (3) laryngeal tuberculosis, (4) pachydermia

$\begin{array}{llcc}\text { laryngis verrucosa } & . & . & 146, \\ \text { case of pachydermia laryngis } & . & \cdot & . \\ \text { case of ulceration of the larynx } & . & . & . \\ \text { on the formation of a circumscribed } & \text { inter-dural abscess at the site } \\ \text { of the saccus endolymphaticus } & .\end{array}$

in intact middle ear .

- appointed pathologist to the Throat Hospital, Golden Square,

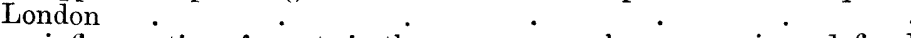

- inflammation of crypts in the mucous membrane covering a defined recess in the roof of the naso-pharynx, giving rise to otalgia and other symptoms . discussion on intra-nasal treatment of ear disease

- on pathology and treatment of toxic paralyses of the larinx

Horse, diphtheria in (L. Cobbett: abstract) .

Hospital of St. Lazar: see St. Lazar.

Huth (Alfred H.), consanguineous marriage and deaf-mutism (abstract).

Hydrochloric acid: ingestion causing pharyngo-nsophageal eschar (Le Gendre: abstract)

Hydrorrhoea, nasal, treatiment with atropine and strychnine (Lermoyez: abstract)

Hypersecretion in case of hysterical paralysis of left rocal cord (C. Chauveau) .

Hypertrophy below vocal cords, cure and relapse (v. Lénart) of the tonsils (H. Cuvellier) tonsillar, treatment by morcellement (Ruault).

Hysteria : a case of hysterical cough (Bournoville: abstract) (Courtade) hysterical deafness cured by suggestion (Taptas : abstract)

abstract) . in a man of thirty-nine (Dr. Hammerschlag:

- true hysterical deafness (Lannois et le MarcHadour : abistract) paralysis of left rocal cord (C. Chauveau)

Ichthyol : therapeutic action in catarrhal inflammation of mucous membrane of larynx (Cieglewicz: abstract).

Ictus, laryngeal (Niel : abstract) 
Indrawing, unusual, of aloe nasi (li. I ake)

Infancy, early, case of adenoids (Jauquet: abstract)

primary atrophic rhinitis commencing in (IV. G. Spencer) . 151

Infant, new-born, first case of Bezold's mastoiditis observed in (Lermoyez) 90

Infection, tonsillar, revealed by morcellement (Castex) $\quad . \quad 89$

Inflammation, catarrhal, of mucous membrane of larynx, therapeutic action of ichthyol on (Cieglewicz: abstract) . . . 98 of accessory sinuses of nose (M. Hajek : review) $\quad . \quad$. 115

- of crypts of mucous membrane covering defined recess in roof of naso-pharynx (W. Jobson Horne) of middle ear: see Otitis media.

- suppurative, of palatine and lingual tonsils (Sendziak : abstract) . 396

INGERSOLL, benign laryngeal tumours (abstract) ․ . . 104

Inhalation: apparatus for inhalations: its application in treatment of laryngeal tuberculosis (P. Lacroix) .

Injections, intra-muscular, in treatment of double abductor paralysis (L. H. Pegler) • • intra-tracheal, in treatment of laryngeal tuberculosis (L. Vacher) . of carbonate of creosote for fotid breath (Bayer: abstract) tracheal, in treatment of pulmonary tuberculosis ( $T$. Morris Murray)

Injury of larynx in a female (L. A. Lawrence) to epileptic causing mastoid clisease, acute otitis media and pyemia (R. A. Wilson : abstract)

Innervation, motor, of the soft palate and larynx (Brindel : abstract) $\quad \cdot 400$

Instruments, new (Suarez de Mendoza) . . . . . . 286 for treatment of antral empyema (Mr. Acland) $\quad . \quad+375$

- used in dentistry: application to nasal surgery (Suarez de Mendoza) see also Forceps.

Insufflator for the accessory sinuses (Lichtwit $\%$ )

Interarytænoid region: ulceration, specimen (shown by Mr. Bergin for Mr. Lake) .

Internal organs: relation of diseases of internal organs to disturbances in upper air-passages (Sokolowski: abstract)

International Medical Congress (Thirteenth), Paris : section of laryngology and rhinology

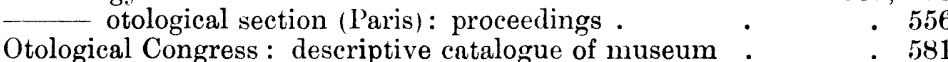

Intoxication: see Auto.intoxication.

Intra-nasal treatment in ear disease, discussion on (opened by P. McBride, p. 471; E. Cresswell Baber, p. 476 ; J. Dundas Grant, p. 479) 471.491

Intubation (Biernacki : abstract) . . . . 98 apart from croup, in the child and adult (A. Lorgnon : abstract) . 338 case in which there was difficulty in removing a tracheotomy tube

(E. W. Roughton) . . . . . . . . 371 difficult : external manipulations in cases of (Fscat) . $\quad .604$ for twelve months in stricture of cesophagus (C. J. Symonds) $\quad 369$ - perichondritis of larynx following introduction or retention of tube in oesophagus (H. T. Butlin) Sajous's cyclopædia of practical medicine (review of article on intubation) without permanent supervision (Escat: abstract)

Iodine and the thyroid gland (I. Gautier : abstract)

Iodine vasogen .

Iodism: "purpura iodique" of the buccal mucosa (G. Milian : abstract). Iodoform spray for chronic periostitis (Ménière)

Irrigator for nasal duct.

JAconson (Alexander), spasmodic rhinitis

JACQUes (P.) and Mrches (G.), dental cysts of the superior maxilla: their relations to the maxillary antrum; their treatment (abstract) 


\section{Index.}

JAUQUET on adenoids in early infancy (abstract)

Jaw (lower) fibrous tumour (T. M. Manley : abstract) . . . 617

(upper), cases of acute osteomyelitis of upper jaw in infants (Ropke: abstract)

- see also Maxilla.

JoAL, carbonic acid in affections of the nose (abstract) . . $\quad .510$

JoHsson, report of an interesting case of dyspncea in an adult (abstract) . 104

Joyce (Robert Dwyer), the topography of the facial nerve in its relation to mastoid operations.

Jugular vein : see Vein (jugular).

KASPARIANT (Dr.), palpation of the maxillary antrum and endo-nasal operation for antral empyema

Kassed (Dr.), on treatment of laryngeal tuberculosis (abstract)
KaUfuaN (Dr.), on case of necessary opening of mastoid to extract foreign body in meatus

Kelling (George), endoscopy of the oesophagus and stomach (abstract)

KELLY (A. Brown), epistaxis from the ethmoidal veins. angina ulcerosa benigna (abstract)

KeLson (William H.), case of laryngeal growth

case of aural exostoses

Killian (Professor Gustav), case of acute perichondritis and periostitis of the nasal septum of dental origin (abstract)

KLEIN (E., F.R.S.), discussion on the pathological distribution of the diphtheria bacillus and the bacteriological diagnosis of diphtheria

KNapp (Herman), two cases of otitic sinus thrombosis, the one fatal, the other ending in recovery (abstract)

Körser (Otto), "Die eitrigen Erkrankungen des Schlafenbeins" (purulent disease of the temporal bone, described according to clinical experiences) (review)

- surgical treatment of suppuration in the labyrinth (abstract)

KïRNER's plastic operation, a modification in operations for cholesteatoma (Professor F. Siebenmann : abstract)

KraUs $(\boldsymbol{H}$.$) , perichondritis laryngea in scarlet fever (abstract) . \quad$ - $\quad 52$

KraUse (Hermann), on singers' nodes (nodules vocaux) • . 565

KyLE (D. Bradon), on a peculiar case of migratory foreign body, with X-ray illustrations.

Labour and pregnancy causing threatening swelling of tumour of the larynx (Dr. Ephraim : abstract)

Labyrinth of ear, pathology and pathological anatomy $(\dot{H}$. Haike: abstract)

suppuration, surgical treatment (Körner: abstract)

LACK (H. Lambert), case of nasal polypi, with suppuration and (?) absence of maxillary sinuses .

a specimen of a curtain ring removed from the pharynx of a child. two cases of nasal polypi treated by a new radical method with microscopic section of the bone removed

case of a male aged twenty with distension of the maxillary antrum

- curtain ring for eight years in pharynx of a child (abstract)

LACrorx, laryngeal and nasal inhaler aural complications of ozena

an apparatus for inhalations; its application in treatment of laryngeal tuberculosis (abstract) . . . .

LAKE (Richard), male with unusual indrawing of the alie nasi $\dot{b}^{-}$ pathological report on a case of acute Ménière's symptoms in
leno-medullary leucocythæmia; anatomical changes found in acute leucocythæmic affections of ear 
LakE (Richard) : specimen mounted to show ulceration of false cords, true cords, and interarytænoid region (shown by Mr. Bergin) specimen showing tubercular ulceration of larynx (shown by Mr. Bergin)

discuss

complete ossiculectomy : removal of remains of drumhead, larger ossicles, and outer attic wall in chronic otitis media (abstract)

LAмв (Tilliam), treatise on nasal suppuration, translated by William Lamb (review)

LANGBoIs, silver cannula fallen into the first division of the right bronchus (abstract)

Lannors et le Marchanour, true hysterical deafness (abstract) .

LAPALLE, statistical tables of 169 autopsies of the accessory sinuses: the relation between empyema and general diseases

LAPERSONNE (F. de), on optic neuritis associated with sphenoidal sinusitis and diseases of the posterior parts of the nasal fossa (abstract)

Laryngectomy, total, for intrinsic cancer of larynx; recovery (J. W. Leech: abstract)

Laryngitis complicating measles (Sevestre and Ausset: abstract) ${ }^{*}$. - hypertrophic, caused by hereditary syphilis (StClair Thomson) - secondary to rhinitis causing hoarseness in a chaff-cutter $(J$. Dundas Grant) tertiary syplilitic, thyrotomy for (IV. G. Spencer) (tubercular), (A. Hamilton Burt) in man aged thirty-one (H. FitzGerald Powell)

Laryngological Society of America, proceedings

- - of Belgium, proceedings

- - of Hungary, proceedings .

-1 of Londor, proceedings

Laryngology, retrospect of (John Macintyre)

Meeting Otology, section of, at British Medical Association Annual

Laryngoplegia, almost complete, in case of tabes (Sir F. Semon)

Laryngotomy : microscopical specimen of growth removed by $(\mathrm{L}$. Browne and W. Wingrave)

. $\quad 51,97,218,290,336,399,444,511,668$ - accidental cauterization by caustic poisons (Courtade) . 93 anatomical and pathological preparations shown by lantern slides

(P. Watson Williams) arthritis (Escat).

benign growth in the larynx causing pulmonary lesion ( $P$. de

Champeaux : abstract) cancer (Duvivier : abstract) ? cancer (Sendziak : abstract) cancer, diagnosis (B. Fraenkel) (Moritz Schmidt)
early diagnosis and treatment (J. N. Mackenzie) indications for operation (Gouguenheim and E. Lombard) intrinsic; total laryngectomy; recovery (J. W. Leech: plea for removal of entire organ and neighbouring area, after naked-eye diagnosis (J. N. Mackenzie) . . . 524 prognosis (Chiari : abstract) . carcinoma (v. Navratil) (E. B. Waggett) cartilages, architecture of (Max Scheier) conditions of throat and larynx simulating and predisposing to tuberculosis (Lennox Browne). cyst of (J. P. Clark)

(II. Ewart and H. B. Roderick : abstract) 


\section{Index.}

Larynx diseases : cases from clinic of Professor Pieniazek, in Hospital of

St. Lazar (Baurowicz : abstract).

- epithelioma: benign neoplasm removed from larynx nine years previously (L. Browne)

fibroma of (A. B. Thrasher)

foreign body (pin) in (Egger)

fracture, direct; stenosis; dilatation ; eure (Boulai)

growth (W. H. Kelson)

in a male aged 25 (H. Fitzgerald Powell)

(anterior commissure) with altered voice extending over

thirty-two years (Hector Mackenzie

ictus laryngeal (Niel : abstract)

importance of examination in aneurysm of aorta (Sendziak:

abstract)

inflammation: therapeutic action of ichthyol on catarrhal inflamma-

tion of mucous membrane of larynx (Cieglewicz: abstract) .

- see also Laryngitis.

inhalation apparatus as applied in treatment of laryngeal tuberculosis (P. Lacroix) .

injury of, in a female (L. A. Lawrence)

involved in growth of pharynx in case of man aged fifty-nine

(E. Furniss Potter)
laryngeal affection in tubercular patient for diagnosis (G. C. Cathcart) crisis in tabetics in relation with the other visceral crises

(Touche: abstract)

$$
\text { forceps, new universal (P. Watson Williams) }
$$
? whistling (Sir F. Semon) .

\section{lupus of (Wyatt Wingrave)}

malignant disease, statistics of operations for (i). B. Delavan)

(?) malignant growth, extra-laryngeal (shown by Mr. E. B. Waggett

for Mr. W. R. H. Stewart)

- motor innervation of (Brindel : abstract)

neoplasms: blood-clots simulating (Semon: abstract)

- new growth (C. Nourse)

nodules (J. Garel and M. Bernard)

obstructed by voluminous tumours of base of tongue (Didsbury)

- obstruction, congenital (C. H. MeIlraith : abstract)

occlusion in typhoid fever (E. B. Waggett)

cedema, acute ; specimen (A. Logan Turner) .

pachydermia laryngis, case (C. A. Parker)

- case (W. Jobson Horne)

treatment with salicylic acid (J. Fein : abstract)

Horne) verrucosa; lantern demonstration

paralyses, pathology and treatment (Watson Williams and W. Jobson Horne)

- perforation, followed by subcutaneous emphysema in phthisical patient (Raviart: abstract) 
Larynx, perichondritis, following introduction or retention of tube in œesophagus (H. T. Butlin)

pin in larynx for two years, removed by endo-laryngeal methods

(A. W. de Roaldes) .

polypus (Gaudier: abstract)

removal, complete, for sarcoma (J. Dundas Grant)

for sarcoma (J. Dundas Grant)

scleroma, primary (Baumgarten)

small silver coin lodged in larynx for four weeks (Walker Downie:

abstract)

- stenosis, due to complication of thyroid cartilages (E. Mayer: abstract)

treated by electrolysis in patient who had worn tracheal

cannula sixteen years (M. Boulay and J. Boulai) .

stereoscopic photography of (Garel : abstract) .

surgery, modern (Gluck)

syphilis, tertiary (Dr. Tresilian)

threatening swelling of tumour of the larynx from pregnancy and

labour (Dr. Ephraim : abstract)

tubercle (C. J. Symonds)

tuberculosis, lantern demonstration (W. Jobson Horne) . primary (S. Bernheim) treatment (Dr. Kassel : abstract)

by intra-tracheal injections (L. Vacher)

(IV. Freudenthal : abstract)

tumour: benign tumours (Ingersoll : abstract)

chromic acid solution (Hamon de Fougeray) ulceration (TI. Jobson Horne) - ulceration (IV. Jobson (case shown by Dr. H. J. Daris for Mr. S. Paget)

Lake) (tubercular) (specimen shown by Mr. Bergin for Mr. R.

and trachea; cancer, palliative treatment; use of rubber catheter as tracheal cannula (A Courtade)

LAURens (G.), the surgery of the sinuses of the face in relation to the surgery of the orbit.

LAw (Edward), case of laryngeal ulceration

case of lupus of the nose in a female aged thirty-five

LAWRENCE (L. A.), microscopical section of a growth removed from the meatus of an elderly woman .

case of injury of the larvnx in a female

case of advanced atrophic rhinitis in a young girl

Lazarus-Barlow (T. S.), discussion on the pathological distribution of the diphtheria bacillus and the bacteriological diagnosis of diph-

LE Damany (L.), an epidemic of simple angina due to streptococcus (abstract) .

Leech (J. W.), case of intrinsic cancer of the larynx; total laryngectomy; recovery (abstract)

LE GENDRE, ingestion of hydrochloric acid, pharyngo-œsophageal eschar, etc. (abstract)

LELAND (George A.), on tonsillar and circumitonsillar abscess (abstract)

Lf Marc Hadour et Lannois, true hysterical deafness (abstract)

LEMoINE (J.), study on tumours of the trachea (abstract)
V. LiNART on chorditis vocalis inferior hypertrophica, cure and
relapse

LENZMANN on ecchondroma of the cricoid cartilage (abstract) $\quad \cdot \quad \cdot \quad 401$ 
LERMOYEz, first case of Bezold's mastoiditis observed in the new-born infant on hysterical nasal insufficiency (abstract)

(abstract) . . . . . . . . . 442

the treatment of eczema of the ear (abstract) . $\quad . \quad 450$

and MAHU (G.), a new method of treating nasal and naso-pharyngeal affection by the application of hot air

Lesion, pulmonary, due to benign growth in the larynx (P. de Champeaux : abstract)

Leucocythæmia, spleno-medullary, acute Ménière's symptoms, anatomical changes found in acute leucocythrmic affections of the ear (F. P. Weber, with pathological report by R. Lake)

symptomatic of lympho-sarcoma of tonsil (C. Chauveau)

LEUTERT-KonigsBerg, bacteriological and clinical studies in the complications of acute and chronic middle-ear suppuration (abstract) $\quad 451$

Levy, sinus thrombosis, cure without operation (abstract) $\quad$. 110

Leukæmia, temporal bone from a case of (Dr. Gromperz) $\quad$. $\quad 324$

Liaras (G.), contribution to the study of tuberculous infection through the nose (abstract) lupus of the ear (abstract).

Lichтwiт, insufflator for the accessory sinuses $\quad . \quad 1 \quad .89$

and the lumen of the canal formed by drilling the alveolus in antral disease

- on disproportion between the frequence of empyema of the nasal accessory sinuses in the living and dead (abstract)

Ligature of internal jugular vein not performed in case of chronic middle-ear suppuration and thrombosis of lateral sinus; recovery (A. H. Cheatle) not practised in operation for thrombo-phlebitis of lateral sinus ; recovery ( $J$. Dundas Grant) - not practised in operation for chronic middle-ear suppura. tion with thrombosis of lateral sinus ; recovery (A. H. Cheatle)

LINDT (W., jun.), rare case of otitic abscesses of the brain; operation; exitus

Lip (lower): deep median furrow of lower $\dot{l i p}$ and $\dot{c h i n}$ (P. Redard and Frank Michel : abstract)

LISTER (Thomas David), discussion on the pathological distribution of the diphtheria bacillus and the bacteriological diagnosis of diphtheria .

LoDGE (Samuel, jun.), two cases of thrombosis of the lateral sinus, in one of which the etiology and pathology were obscure .

LöFFLER's bacillus : see Bacillus.

LogAN (J. E.) on atrophic rhinitis

Lombard (E.) and GovgunnherM, indications for operation in cancer of the larynx

LORGNON (A.) on intubation and tracheotomy apart from croup in the child and adult (abstract).

Lozenge, Rogers' Modified Lozenge (new preparation)

LUC on mucocele of the frontal sinus (abstract) painful recurrent catitrrh of the frontal sinus, due to stenosis of the fronto-nasal duct

LucAe (A.), profuse escape of cerebro-spinal fluid for five weeks without cerebral symptoms (abstract)

Lungs : emphysema, due to experimental nasal obstruction (Cousteau)

Lupus of the ear (G. Liaras : abstract) of fauces and larynx (Wyatt Wingrave) of the nose (E. Law)

treatment (Ripault: abstract)

Luschka's tonsil : see Tonsil (Luschka's). 
Lymphangioma (?), growth removed from right ventricular band of man aged forty (E. Furniss Potter) .

Lymphatics, obstructed subdermal, of face, ease in which frontal and antral disease had been suspected (P. de Santi) . . . 264

Lympho-sarcoma of tonsil (Gaudier: abstract) . . . 206 leucocythrmia symptomatic of (C. Chauveau) .

MCBRIDE (P.), opening of discussion on intra-nasal treatment in ear disease MACASKIE (James G.), removal of a foreign body from the ear (abstract). MACCALLUM (J. M.), complications of suppuration of middle-ear (abstract) - scarlatinal otitis media; intermittent suppuration for six years; thrombosis of sigmoid and lateral sinus; operation : meningitis; death (abstract) .

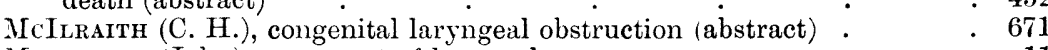

MACINTYRE (John), retrospect of laryngology $: \quad 11$

on the Riontgen rays in diseases of the nose, throat, and neighbouring organs (abstract)

MackaY (W. A.), a case of cesophagotomy (abstract) $\dot{.}$.
MaCkENZIE (Hector), a case of laryngeal growth (anterior commissure) in a man with altered roice for over thirty-five years

MAckenziE (J. N.) on the early diagnosis and treatment of laryngeal cancer

a plea for early naked-eye diagnosis and removal of entire organ, with the neighbouring area of possible lymphatic infection, in cancer of larynx

Ickeows (David), auditory results of removal of post-nasal adenoids; modified operation .

Macnaughton-Jones, case of contracted meatus from chronic otitis media

MCWEENEY (E. J.), rupture of the apparently healthy oesophagus (abstract)

Magnifier in otoscopy (G. Boenninghaus : abstract)

MAHU (G.) and LERMOYEZ (M.), a new method of treating nasal and nasopharyngeal affections by the application of hot air

471

673

452

Maluerbe (M.), report of Committee of Society of Laryngology, Paris, on results of his operation of clearing out mastoid in chronic otitis media

Malignant disease of larynx: statistics of operations for (D. B. Delavan) .

(?) growth, extra-laryngeal (shown by Mr. E. B. Waggett for Mr. W. H. R. Stewart) · • . neoplasm simulated by syphilitic tumour of the tonsil (Ciechomski : abstract)

Maxasse (P.) and Wintermantel (A.), report of seventy-seven radical operations (abstract)

Manipulations, external, in cases of difficult intubation (Escat) :

Mat) $\cdot * 604$

MANLEY (Thomas M.), fibrous tumour of lower jaw (abstract) • • • 617

Theroid tumour (abstract) - $\quad \cdot \quad 618$

MaRIaN, the soft palate an organ of taste (abstract) . . . . 395 a case of chancriform angina (abstract) $\quad . \quad 5 \quad .440$

Marriage, consanguineous, and deaf-mutism (A. H. Huth : abstract) . 446

MARX (1)r.) on case of girl aged seventeen with large heart-shaped perfora- 323 tion of the membrana tympani, showing carotid artery . . 323

MARTis, hæmorrhage following adenoid operations (abstract) $\quad \cdot \quad 49$

report of a case of empyema of the frontal sinus, with orbital abscess; operation and cure (abstract) . . . . . 105

Martuscelli $(G$.$) , experimental researches on the olfactory bulbs (abstract)$

Masini, have the tonsils an internal secretion ? (abstract)
Vassage (internal) of mucous membrane of nose and naso-pharynx (Browicz: abstract). . . . .

Massei (Prof. F.) on the laryngeal complications of cutaneous sarcomatosis

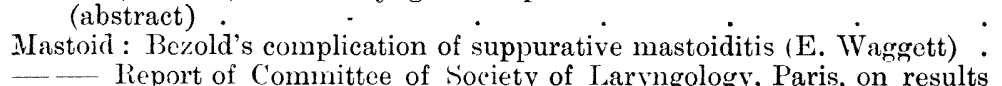
of all Malherbe's operation of clearing out mastoid in sclerotic otitis media 
Mastoid, method of closure of bone defects in (Von Mosetig-Moorhof : abstract). disease and cerebral abscess in case of suppurative otitis; necropsy

(H. Blake : abstract) William Dalby) - (complete), selection of suitable cases for the cure of chronic suppurative disease of the middle ear (A. E. Cumberbatch) . conduct of, for cure of chronic purulent otorrhoea, with special reference to immediate healing of cavity in bone by epithelial grafts (Charles A. Ballance)

abstract) early suture of retro-auricular incision after (Botey :

- followed by acute bilateral (double) brain abscess; recovery (H. Seligman : abstract) ${ }^{2}$ necessary for extraction of foreign body from meatus (Kaufmann)

(Stacke s), eighty successive cases (P. Jakins : abstract) :

abstract) statistics of dangerous complications (M. Teichmann: Jones) topography of facial nerve in relation to $(\dot{\mathrm{R}}$. Dwyer

- - large subperiosteal abscess over the base of the mastoid process (Hasslauer : abstract) .

Mastoiditis, acute, discharging into meatus (Weissmann : abstract) $\quad .114$

Bezold's : first case observed in new-born infant (Lermoyez) $\quad .90$

- central, diagnosis by new method of auricular auscultation (Ostino:

(axilla (inferior) : median division, with deep median furrow of lower lip and chin and malformation of tongue (P. Redard and Frank Michel: abstract)

(superior) dental cysts ; relations to maxillary antrum (P. Jacques and G. Michel : abstract) dentiferous cyst of (P. Berger: abstract)

Maxillary antrum: see Antrum (maxillary).

sinus: see Sinus (maxillary).

MAYER (Emil), on recurring membranous faucitis due to bacillus of Fried-

lander; report of case

- laryngeal stenosis due to complication of the thyroid cartilages

(abstract).. .670

Neasles, laryngitis complicating (Sevestre and Ausset : abstract) $\quad: \quad 445$

Meatus : acute mastoiditis discharging into (Weissmann: abstract) $\quad .114$

- and adjacent parts: antiseptic purification (U. Pritchard) 123, 137

- auditory, acquired atresia and stricture (H. Schwartze : abstract) . 674

- cholesteatoma removed through (U. Pritchard) . . 143

contracted, from chronic otitis media (Macnaughton-Jones) : 316

- epithelioma of (Arthur Cheatle) . . . 316

- external auditory, cavernous angioma of (Hennebert: abstract) : 206

-1 eyst on the floor of (Dr. Ephraim : abstract) $\quad: 220$

-1
-1
- auricular, endothelial fibro-angioma of (Urbano Melzi)

growth removed from (L. A. Lawrence) meatus (Kaufinann). . . . 144

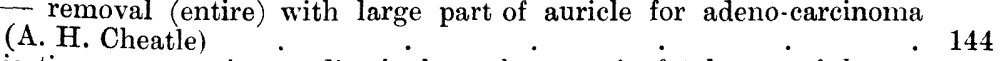

Mediastinum: extensive imediastinal emphysema in fatal case of laryngeal diphtheria (TI. Ewart and H. B. Roderick: abstract) . . 171

Medical Annual, (1900), (review) . $. \quad . \quad .679$ 
Medulla: see Brain.

van Melle and Vaschide on a new hypothesis as to the nature of the physies of odours (abstract)

Melzi (Urbano) on a case of retropharyngeal abscess of auricular origin . on a case of endothelial fibro-angioma of the external auricular meatus

Membrane, tympanic: see Tympanic membrane.

MÉneaU, a case of argyrism of the skin and mucous membranes due to repeated cauterization of the pharynx with silver nitrate (abstract) . 105

Múnİ̀RE, iodoform spray for chronic periostitis $\quad$. $\quad$. $\quad$. 91

MÉnIL̀RE's disease, causes and treatment of . . . . . . 562 abstract) - symptoms (acute) in spleno-medullary leucocythæmia; anatomical changes found in acute leucocythæmic affections of ear (F. P. Weber, with pathological report by R. Lake)

- vertigo (U. Pritchard)

Meningitis : common forms, with special reference to serous meningitis (C. L. Dana : abstract)

(fatal), following operation for thrombosis of sigmoid and lateral sinus (J. M. MacCallum: abstract)

Menstruation through the right ear (Lermovez: abstract) .

Menzel (M.), on pemphigus of the mucous membranes (abstract) .

Meslay and Viollet (S.), bacteriological examination of four cases of atrophic rhinitis (abstract)

Metropolitan Ear, Nose, and Throat Hospital, bequest to
Michel (Frank) and Redard (P.), deep nedian furrow of the lower lip and chin, median division of the inferior maxilla, and malformation of the tongue (abstract)

Michel (G.) and JACQUes (P.), dental cysts of the superior maxilla: their relations to the maxillary antrum : their treatment (abstract)

Milian (G.), "purpura iodique " of the buccal mucosa (abstract)

Milla Rd (C. Killick), a case of membranous angina and membranous vaginitis of a doubtfully diphtheritic nature occurring in a patient convalescing from scarlet fever, and associated with an unusual erythematous eruption (abstract)

Milligan (W.), recent progress in the treatment of some of the dangerous complications of suppurative middle-ear disease (abstract) .

- a case of cerebellar abscess recently operated upon, with specimens of abscess of the cerebellum following chronic middle-ear suppuration .

Mintz on diagnosis of diverticulum cesophagi (abstract)

MIот on the use of bleeding and refrigerants in the treatment of acute otitis media, specially in children (abstract)

MoHrive on membranous occlusion of the trachea (abstract)

Mols (Dr.), on causes and treatment of Ménière's disease $\quad . \quad 562$

Morcellement of tonsils revealing infection (Castex) . $\quad . \quad 89$

- in treatment of tonsillar hypertrophy (Ruault) . $\quad . \quad .600$

MorkLLI on multiple angiomata of the tongue . . . 326

von Mosetig-Moorhof, closure of bone-defects in the mastoid by a flap of skin turned up and tucked in under the loosened edges of the opening (abstract)

Mounier, cysts of the tonsils (abstract) - on the importance of auto-intoxication in periodic and aperiodic coryza

Motre (E. J.), treatment of deflections of the septum. .

Movret, noises in ear due to spasmodic contraction of the tensor tympani or of the dilators of the Eustachian tube (abstract)

Mouth, abstracts of literature on . $\quad 46,96,210,287,327,395,439$ successful extirpation through mouth of primary sarcoma of tonsil

(J. Walker Downie) .

tracheotomy in bucco-pharyngeal operations (Delagénière: abstract)

Iouth, ulcer, perforating (Compaired : abstract)

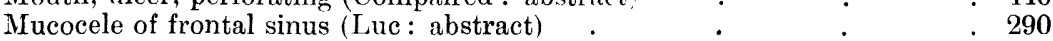


Mucous membrane: argyrism of mucous membranes due to repeated cauterization of pharynx with silver nitrate (Méneaux : abstract) . 105

- (buccal) : "purpura iodique" of (G. Milian : abstract) cystic degeneration of, in nose and accessory sinuses (Fr.

Schlagenhaufer : abstract) inflammation of crypts of mucous membrane covering defined recess in roof of naso-pharynx (IV. Jobson Horne) . internal massage of mucous membrane of nose and nasopharynx (Browiez: abstract). (nasal) : œdema (Gradle : abstract) pemphigus of (M. Menzel : abstract)

AC:E with atresia of the larynx (Otto: abstract) tumours by chromic acid solution (Hamon de Fougeray) . . 605

Membrana tympani : pathology of relaxation (Gruber: abstract) $\quad$. 109

- rupture, multiple (Overacher : abstract) $\quad$ - $\quad 57$

MüLlER (Richard), effect of artillery practice on the ears (abstract) . 228

Muir (R.), discussion on the pathological distribution of the diphtheria bacillus and the bacteriological diagnosis of diphtheria

Murray (T. Morris), on tracheal injections in treatment of pulmonary tuberculosis

Nuseum of International Otological Congress : descriptive catalogue 581,678

Myles (R. C.), elected Professor of Laryngology and Rhinology at the New York Polyclinic

Myringitis, chronic dry (Stetter : abstract) . $\quad . \quad+\quad . \quad 113$

Myxœdema. co-existing in fatal case of Graves' disease (M. Faure : abstract) 102

Myxofibroma (?) of the post-nasal space (H. FitzGerald Powell) . $\quad 77$

NADoLECzNy (M.), bacteriological and clinical examination of genuine acute exudative middle-ear inflammation (abstract)

Naked-eye diagnosis: see Diagnosis, naked eye.

Naso-pharynx : bloodless operation for naso-pharyngeal polypi (Schmithuisen : abstract) considerations on the operative treatment of fibrous naso-pharyngeal polypi (Delie : abstract)

diphtheria of pharynx and naso-pharynx with multiple abscesses of tonsils and empyemata of Highmore's antra (Sendriak : abstract) discharge of pus and blood for over twelve months (Barclay Baron)

growth in (?) sarcoma (L. H. Pegler) $\quad$ - $\quad$. hot air in treatment of naso-pharyngeal affections (M. Lermoyez and G. Mahu) . . . . . - inflammation of crypts of mucous membrane covering defined recess in roof of naso-pharynx (IV. Jobson Horne) . internal massage of mucous membrane of naso-pharynx (Browicz: abstract) pseudo-hæmoptysis arising in (R. Botey) $\dot{ } \cdot \dot{ }$
recesses in, produced by approximation of remains of Luschka's tonsil and Eustachian cushions (StClair Thomson)

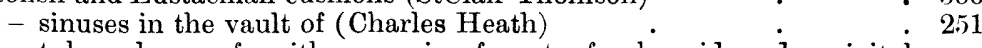

$\quad . \quad 366$

tuberculoma of, with necrosis of part of sphenoid and occipital bones (Schmithuisen : abstract)

NAtier, three cases of spontaneous hæmorrhage from the septum (abstract)

von Navratil (E.), on carcinoma of larynx . operative treatment of scleroma

Neck, cellulitis (Plücker : abstract) Grant)

- enlargement, rapid, of cervical glands in elderly woman $\dot{(J}$. Dundas growth in, associated with cedema of one aryepiglottic fold

(J. Dundas Grant) . . . . . . 388 tumour in neck containing gas (Guinard : abstract) $\quad . \quad 4 \quad$. 446 
Necrosis, extensive, following nasal polypi and sinus disease (W. G. Spencer) of sphenoid and occipital bones with tuberculoma in naso-pharynx (Schmithuisen : abstract)

Ni:Laton, a new method of rhinoplasty (abstract)

Neoplasm (laryngeal), blood-clots simulating (Sir F. Semon : abstract) : 106

Nerve, auditory, central connections (W. A. Turner) . $\quad . \quad 131$

facial : topography in relation to mastoid operations (R. D. Joyce) 23

- pneumogastric: removal of portion of pneumogastric nerve together with sarcoma of carotid sheath (Scanes Spicer and Stans. field Collier : abstract)

Neurans on the nasal douche and its substitute (abstract)

and its substitute (abstract) $\quad \cdot \quad 667$

Neuralgia, facial, cases of aural origin (Sarremone) . $\quad . \quad .286$

Neuritis, optic, associated with sphenoidal sinusitis and diseases of posterior parts of nasal fossæ (Lapersonne: abstract)

NicolL (J. H.) and BARR (T.), cases of thrombosis of the lateral sinus. consequent upon purulent inflammation of middle ear; opening of sinus; ligature of internal jugular vien; recovery (abstract)

NiEL, contribution to the study of laryngeal ictus (abstract)

Nodes (singers') : see Singers' nodes.

Nodules, laryngeal (J. Garel and M. Bernard) vocal (O. Chiari) .

Noises in ear due to spasmodic contraction of tensor tympani or of dilators of Eustachian tube (Mouret : abstract) . . . . 453

Nose, abstracts of literature on $\quad .47,97,212,289,331,397,441,510,617,667$ - accessory sinuses, inflammatory affections (M. Hajek : review) . 115 - adeno-sarcoma of nasal septum (Baker : abstract) . $\quad .212$ alæ nasi, unusual indrawing (R. Lake) . . $\quad . \quad 41$ and accessory cavities: anatomical and pathological preparations shown by lantern slides (P. Watson Williams)

- blowing of nose cause of emphysema of orbital wall of anterior ethmoidal cells (J. Dundas Grant)

bridge-like synechiæ between septum and inferior turbinated body

(J. Dundas Grant)

bullet-wound in the head; removal of bullet from nose twenty months afterwards (Claud Woakes : abstract)

calculus: see Rhrnolith.

carbonic acid in affections of (Joal: abstract) .

catarrh, nasal ; prevention (Rogers : abstract) .

abstract) cystic degeneration of mucous membrane in nose and accessory sinuses (Fr. Schlagenhaufer : abstract).

deflections of cartilaginous septum, Asch's operation for (Thorner: abstract)

\section{of the septum; treatment (E. J. Moure)}

.. diagnosis and treatment of chronic purulent nasal discharges:

rhinoscopy and special methods of diasnosis (F. W. Roughton) 238,

(diseases): cases from clinic of Professor Pieniazek in hospital of

St. Lazar (Bourowic $z$ : abstract)

abstract) quarterly retrospect of department for (G. T. Ross:

distension, great, of bridge of nose in case of double frontal sinus

and antral empyema (H. Tilley)

electrolysis in nasal diseases (D

fibro-myxoma of post-nasal region, case after removal (H. Fitz-

Gerald Powell)

fibro-sarcoma with unusual course (Sendziak : abstract)
fractures of the nose (T. A. De Blois)

hæmorrhage, spontaneous, from septum (Natier : abstract) $\quad . \quad 97$

- hot air in treatment of nasal affections (M. Lermoyez and G. Mahu) 597 
Nose, hydrorrhoa, treatment with atropine and strychnine (Lermoyez:

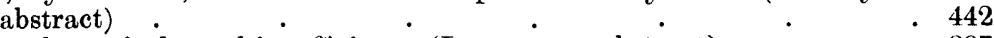
hysterical nasal insufficiency (Lermoyez: abstract) . . $\quad 397$ internal massage of mucous membrane of nose (Browicz: abstract) 397

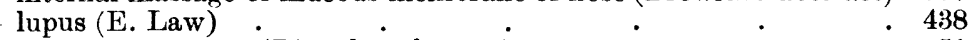
- treatment (Ripault : abstract) . $\quad 51$ myxofibroma of post-nasal space (H. FitzGerald Powell) ${ }^{\circ} \quad$. $\quad 77$ nasal and aural speculum-holder (Courtade) . $\quad . \quad 993$ - and laryngeal inhaler (Lacroix) $\quad . \quad 1098$ douche and its substitute (Neumann : abstract) $\cdot \cdot \quad \cdot 667$ - duct irrigator . . . . 118 - polypi followed by extensive necrosis (W. G. Spencer) $\quad . \quad 370$

$\begin{array}{lll}- & 429 \\ - \text { radical operation for (C. A. Parker) } & \\ \text { treated by a new radical method (H. Lambert Lack) } & 380\end{array}$ (H. Lambert Lack). with suppuration and (?) absence of maxillary sinuses stenosis (B. S. Booth : abstract) negative air-douche as aid to diagnosis of diseases of nasal accessory cavities (L. Réthi : abstract)

(obstruction): pulmonary emphysema due to experimental nasal obstruction (Cousteau)

- radical cure of nasal obstruction (Suarez de Mendoza: abstract) . . . . . . . . . - adema of nasal mucous membrane and cedematous occlusion of nasal passages (Gradle : abstract)

- optic neuritis associated with sphenoidal sinusitis and diseases of posterior parts of nasal fossie (Lapersonne: abstract)

- - perichondritis and periostitis (acute) of the nasal septum of dental origin (Professor Gustav Killian : abstract)

(polypus) radical operation for nasal polypi (C. A. Parker)

post-nasal adenoids : see Adenoids (post-nasal). - growth considered persistence of adenoids (E. Furniss Potter) purulent nasal discharges, chronic (Herbert Tilley) (Dundas Grant)

rhinos their diagnosis and treatment;

rhinoscopy and special methods of diagnosis (E. W. Roughton)
Roughton : review). They : review)

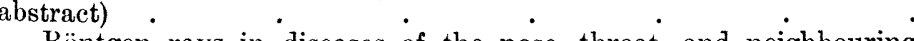

Rontgen rays in diseases of the nose, throat, and neighbouring

organs (Joln Macintyre : abstract)

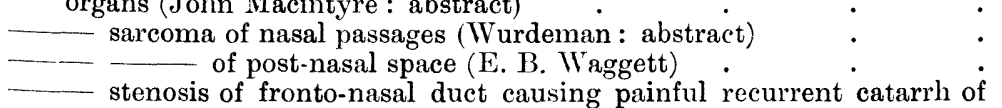

frontal sinus (Luc).

nasal cavities (J. Veis: abstract)

surgery, application of instruments used in dentistry to (Suarez

de Mendoza) . . . .

surgical treatment of some common forms of nesal insufficiency

(L. H. Pegler) swelling about bridge of nose (case shown by Mr. E. B. Waggett

for Mr. W. R. H. Stewart) synechia (J. D. Grant)

synechiæ, nasal and post-nasal (J. Price Brown)

syphilis, tertiary (Tresilian)

treatise on nasal suppuration (I. Grïnwald : review)

treatment of digestive disorders associated with chronic rhino-

pharyngitis (Aviragnet: abstract) 
Nose, tuberculosis (Texier and Bar) . b11 vegetating (G. Prota: abstract) . . . 215 tuberculous infection through the nose (G. Liaras: abstract) tumour of nasal septum [angiosarcoma] (Herbert Tilley) 265, 369

- malignant of mucous membrane; treatment by chromic

acid solution (Hamon de Fougeray) . $\quad . \quad 605$ ulceration of al:e nasi (C. A. Parker) . . $\quad . \quad 86$ syphilitic (Wyatt Wingrave). $\quad . \quad 665$ tertiary specific, of ala nasi (J. Dundas Grant) . 85 use of suprarenal capsule in the nose and throat (.I. ('. Sharp: abstract) year-book (G. P. Head and A. H. Andrews: review) $\quad \cdot \quad \cdot \quad 37$ and throat diseases (J. Price Brown : review) . . 450

_- see Endo-nasal operation; Intra-nasal treatment; Naso-pharynr.

Nostril: obstruction of one nostril from antral affection of uncertain

character (StClair Thomson). . . 254

Notation, acoumetric, universal (F. Schiffers and A. Hartman) . $\quad 556,558$

Noursw (Chichele), a case of laryngeal new growth . $\quad . \quad 662$

Novol (G.), the pneumatic treatment of diseases of the ear $\quad . \quad 70$

Obituary notices : Nrs. A. C. Daly, of Pittsburg _ . $\quad$. 63 - Professor Charles 1)elstanche $\quad$. $\quad$. $\quad$. $\quad$. 121 Professor Joseph Gruber . $\quad . \quad$. $\quad . \quad 237$ William Macneill Whistler $\quad . \quad$. $\quad . \quad 181$

Obraszoff (H.), case of eclampsia due to paracentesis (abstract) . $\quad 568$

Obstruction, congenital laryngeal (C. H. McIlraith : abstract) . . 671 experimental nasal, causing pulmonary emphysema (Cousteau) . 604 (nasal) in cases of chronic purulent nasal discharges (E. W. Roughton) . of one nostril from antral affection of uncertain character (StClair

Thomson) . . . . . . . . . 254

Occlusion of choane, bony : radical operation (T. S. Flatau : abstract) $\quad 47$

of larynx in typhoid fever (E. B. Waggett) . . . 431 of nasal passages, odematous (Gradle: abstract) . . 48 of the trachea, membranous (Mohinie: abstract) $\quad . \quad \cdot \quad 291$

Odours, the physics of : a new hypothesis as to their nature (ran Melle and Vaschide : abstract). . . . . . . . . 398

(Edema of glottis : lantern demonstration ( W. Jobson Horne) . $\quad$. 146

$\ldots$ acute, of the larynx: specimen (A. Logan Tumer) . . . 373

- of nasal mucous membrane and adematous occlusion of nasal passages (Gradle : abstract) . . . . . . 48

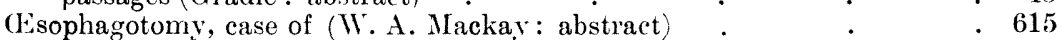

(Esophagus : cancer, spreading to treachea (Appert: abstract) . . 511 carcinoma, pharrngo-esophageal (W. G. Spencer) $\quad . \quad 150$ diverticulum osophagi (Mint\%: abstract) $\quad . \quad$. $\quad .396$ endoscopr of (G. Kelling: abstract) $\quad . \quad 4 \quad 676$

perichondritis of larynx following introduction or retention of tube

in (esophagus (H. T. Butlin) . . . . . 428

- pharyngo-(esophageal eschar caused by ingestion of hydrochloric

acid (Le Gendre : abstract) . $\quad . \quad$. $\quad . \quad 624$

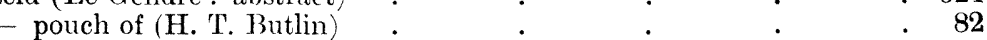
rupture when apparently healthy (F. J. McWéney : abstract) $\quad . \quad 676$ ruptured by vomiting, with table of hitherto recorded cases

(R. L. Bowles and G. R. Turner) $\quad . \quad 2 \quad . \quad 250$

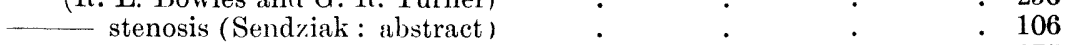

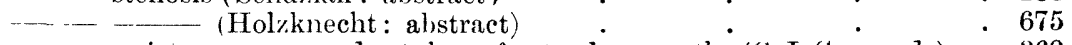
stricture : case under tubage for twelve months (C.J.Symonds) . 369

tumours of the c'sophagus removed by subhyoid pharyngotomy

(IV. Permewan: abstract)

Olfactory bull)s : see Bulb (olfactory).

ONODI (A.), anosmia

Open-air treatment of tuberculosis, British sanitoria for (review) 
Ophthalmoscopic examination important in purulent affections of the ear (Delstanche, jun. : abstract)

Oppenheim on the so-called Ménière's disease (vertigo ab aure læsa; vertigo auralis) (abstract)

Orbit, surgery of, in relation to surgery of sinuses of face (G. Laurens) . 608

Orthoform, action of (1)r. (iomperz)

Ossiculectomy, complete, in chronic otitis media (11. Lake: abstract) $\quad \cdot 621$

— followed by healing (C. H. Fagge) . . • . 316

Osteomyelitis, acute, of upper jaw in infants (Ropke : abstract) . $\quad 330$

Ostrino: a new method of auricular auscultation in the diagnosis of central mastoiditis (abstract)

Ostium maxillare, catheterization through, in purulent nasal discharges (E. W. Roughton)

Otalgia and other symptoms caused by an inflammation of crypts in mucous membrane covering defined recess in roof of naso-pharynx (IT. Jobson Horne) . . . .

Otitis, cerebellar abscess due to (Hansberg : abstract) . $\quad . \quad 110$

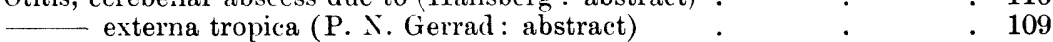

- acuta: cases in which early paracentesis of tympanic membrane is important ( $\mathrm{K}$. Fullerton : abstract) children (Miot: abstract) . . . . . - following mastoid disease, the result of injury in an epileptic (R. A. Wilson : abstract complete ossiculectomy in (R. Lake : abstract)

genuine, acute exudative, bacteriological and clinical ex-

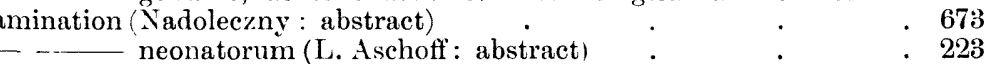

- residua, chronic suppurative : synechiotomy of stapes for improving hearing in (E. B. Jench: abstract) . . scarlatinal, followed by intermittent suppuration for six years (J. M. MacCallum : abstract)

sclerotic : report of committee of Society of Laryngology, Paris, on results of M. Malherbe's operation of clearing out mastoid in sclerotic otitis media

spontaneous cure (Hammerschlag: abstract) $\cdot \dot{ }$
suppurative, cases of dangerous sequelæ (crunert and

Zeroni) . otitic abscesses of brain, rare case (W. Lindt, jun. : abstract)

- sinus thrombosis, two cases (H. Knapp: abstract) $\quad 449$

- - suppurativa, followed by cerebellar abscess (Honain : abstract) . 445

- suppurative: treatment of acute and chronic suppurative otitis with formol (Vacher : abstract)

(H. Blake : abstract)

. 61

Otological Congress, Sixth International $\quad \cdot \quad \cdot \quad \cdot \quad \cdot \quad 13,64,131$

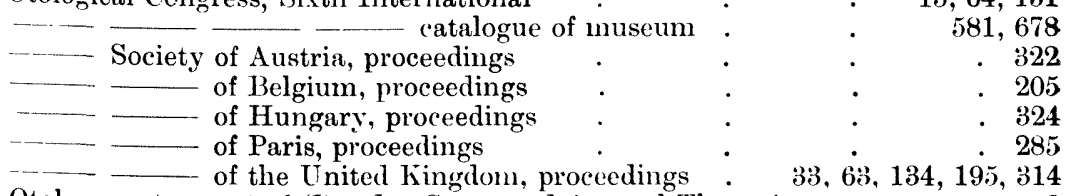

Otology, retrospect of (1)undas Grant and Atwood Thorne) ${ }^{33,63,134,195,314}$

- and Laryngology, section of, at British Medical Association Annual Meeting

Otorrhwea (chronic purulent) : cases of chronic purulent otorrhœea suitable for the mastoid operation (Sir William Dalby)

cure of, by mastoid operation, with special reference

to immediate healing of cavity in bone by epithelial grafts (Charles

A. Ballance) 
Otoscopy, magnifier in (G. Boenninghaus : abstract)

OTTo, a case of chronic pemphigus of the mucous membrane of the upper air-passages and of the conjunctiva, with atresia of the larynx (abstract)

OUSPENSKI, reciprocal influence of the affected upon the normal ear (abstract)

Overacker, multiple rupture of the membrana tympani (abstract) - $\quad 57$

Ozæna : aural complications (P. Lacroix) . $\quad . \quad$. 134

- bacteriological and histological study of (Cozzotino : abstract) $\quad$ - 332

case of probable sphenoidal origin (J. W. Farlow) . $\quad . \quad 309$

_- its pathogenesis and relations to sinusitis (George Paul : abstract) $\quad 334$

Pachydermia laryngis : case (C. A. Parker) . . . . . 266

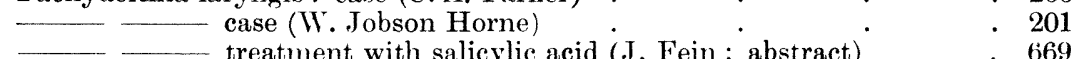

verrucosa : lantern demonstration (W. Jobson Horne) $\quad 147$

Packard (F. R.), innocently-acquired syphilitic infection of the throat (abstract).

Pager (Stephen), case of tracheal stenosis (shown for ilr. Pasteur) $\quad . \quad 374$

Palate, chancre of (G. Baudouin : abstract). . . . 395

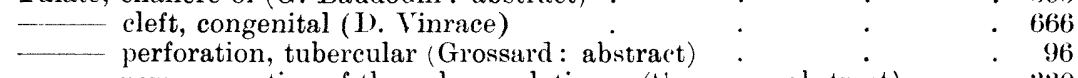

- perverse action of the velum palatinum (Saenger : abstract) . $\quad 3: 30$

vocal cord (C. Chauveau)

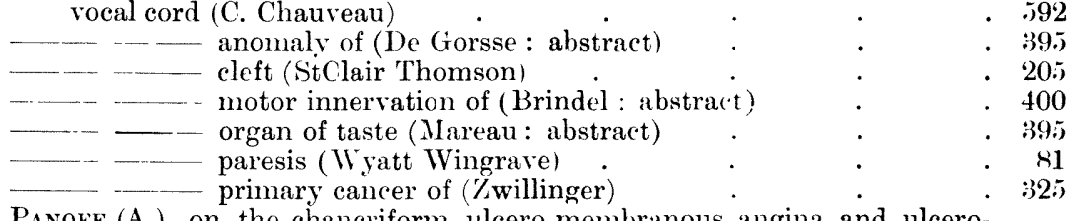

Panoff (A.). on the chancriform ulcero-membranous angina and ulceromembranous stomatitis with Vincent's fusiform hacilli and spirillæ (abstract) .

Papilloma (larynx), papillomata of larynx in children (F.. T. Dickerman: abstract) . $\quad . \quad 6 \quad .668$

unusual papillomatous growth in larynx (.T.S. (iibb:abstract) 669

- recurrent papillomata of larynx (A. Bronner) $\quad . \quad 80$

Paracentesis causing eclampsia (H. Obraszoff : abstract) $\quad \cdot \quad \cdot \quad$. $\quad .58$

- early, of tympanic membrane, important in certain cases of otitis media acuta (K. Fullerton : abstract) . . . . . 226

Paræsthesia, laryngeal, pathogenesis and treatment (R. Botey) . $\quad$. 602

Paralysis, bilateral abductor (Wyatt Wingrave) $\quad . \quad 392$

- under treatment by intra-muscular injections (L. H.

Pegler)

aneurism of the arch of the aorta (Courtade: abstract) . $\quad 337$

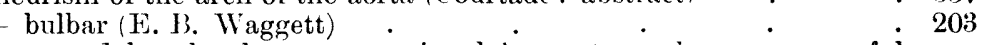

- caused by alveolar sarcoma involving petrous bone; successful

operation (Charles A. Ballance) . . . . 315

- causes and prognosis of facial palsy following operation (Castex) $\quad$. 285 - complete abductor, of left vocal cord (Mayo Collier) . . 268

- (diphtheritic) in cases treated with antitoxin (F. J. Woolacott:

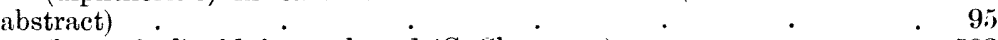

(hysterical) of left vocal cord (C. (hauveau) $\quad . \quad+\quad . \quad 592$

of larynx (G. T. Ross: abstract) . $\quad . \quad 55$

laryngeal paralysis, pathology and treatment (Watson

Villiams and W. Jobson Horne) . . . . 540 partial, of vocal cords; due to over-use of telephone (C. C. Rice) $\$ 310$

Parasitic affections of the pharynx (Sisson : abstract) . . 231

Paresis of left sterno-mastoid and trapezius muscles in case of hysterical

paralysis of left vocal cord (C. (hauveau) 
Paresis of soft palate (Wyatt Wingrave)

(C. Chauveau)

PARker (C. A.). ulceration of alæ nasi

case of pachydermia laryngis

case of radical operation for nasal polypi

Parry (L. A.), hemiatrophy of the tongue (abstract)

Pasteur (W.), case of tracheal stenosis (shown by Mr. Stephen Paget)

Pathology of middle ear and labyrinth (H. Haike : abstract)

$$
\text { obscure, in case of thrombosis of lateral sinus (S. Lodge, jun.) }
$$

of petro-squamosal sinus (A. H. Cheatle)

of relaxation of membrani tympani (Gruber: abstract) .

pathological distribution of diphtheria bacillus (discussion opened

by F. W. Andrewes, Brit. Med. Assoc.) .

PACL (George), pathogenesis of ozæna and relations of ozæna to sinusitis (abstract) .

Pedunculated tonsil ( $\mathrm{H}$. Tilley)

Pegler (L. H.), case of double abductor paralysis under treatment by intramuscular injections .

- case of intractable aphonia, with occasional apsithyria $\cdot$

case of naso-pharyngeal growth (" sarcoma) .

on the surgical treatment of some common forms of nasal insufficiency

discussion on intra-nasal treatment of ear disease
Pemphigus of the mucous membranes (MI. Menzel: abstra

(chronic) of the mucous membrane of the upper air-passages and of the conjunctiva, with atresia of the larynx (Otto: abstract)

Penjered (Vaughan), four cases of otitis media (abstract) . $\quad . \quad 11$

Percussion of the mastoid process (H. Eulenstein : abstract) $\quad . \quad+402$

Perforation healed by application of trichloracetic acid (J. J)undas (irant) 316

- laryngeal, followed by subcutaneous emphysema in phthisical patient (Raviart : abstract)

- of membrana tympani, large heart-shaped, showing carotid artery

in girl aged seventeen (Dr. Marx)

tubercular, of palate (Grossard : abstract)

(Professor Gustav Killian : abstract)

- laryngea in scarlet fever (H. Kraus : abstract).

laryngeal, complicating pulmonary tuberculosis (R. H. Scanes Spicer)

of larynx following introduction or retention of tube in cisophagus

(H. T. Butlin)

Periostitis and acute perichonditis of the nasal septum of dental origin

(Professor Gustav Killian : abstract) . . . chronic, iodoform spray for (Ménière)

Peritonsillitis (phlegmonous), importance of upper portion of tonsil and of supra-tonsillar fossa in wtiology of (R. Botey).

PerMewan (W.), atrophic rhinitis with general systemic infection (abstract) cases of tumours of the cesophagus removed by subhyoid pharyngotomy (abstract)

Persistence of the lower portion of thyroglossal duct (A.'T. Bazin : abstract)

Petro-squamosal sinus: see Sinus (petro-squamosal).

Pharmaceutical preparations

Pharrngitis, chronic, treatment (C. Savoire) .

Pharyngotomy, subhyoid, for removal of tumours of the a'sophagus (W. Permewan : abstract)

Pharynx : abnormal pulsating pharyngeal vessel (H. Tilley) $\cdot{ }^{\prime} \cdot{ }^{2} 1$

abstracts of literature on $\quad: 231,624,675$ anatomical and pathological preparations, shown by lantern-slides

(P. Watson Williams)

- atrophy (R. W. Seiss : abstract) $\cdot{ }^{\circ} \cdot{ }^{\prime}$ 
Pharynx: curtain-ring for eight years in pharrnx of child (H. L. Lack: abstract)

diphtheria of pharynx and naso-pharyx, with multiple abscesses of tonsils and empyemata of Highmore's antra (Sendziak: abstract) growth, involving larynx, in case of man aged fifty-nine (E.

Furmiss Potter)

- growth, naso-pharyngeal (?' sarcoma) (L. H. Pegler) parasitic affections of (Sisson: abstract) $\quad . \quad 231$

pharyngo-nesophageal eschar caused by ingestion of hydrochloric acid (Le Gendre : abstract)

repeated cauterization with silver nitrate, causing argyrism of skin and nucous membranes (M'́neau : abstract)

stenosis, severe pharyngeal, not of syphilitic origin (Swiatecki: abstract)

syphilis, tertiary (Dr. Tresilian)

tracheotomy in bucco-pharyngeal operations (Delagénière: abstract)

treatment of digestive disorders associated with chronic rhinopharyngitis (Aviragnet: abstract)

_- tumours, malignant, of mucous membrane: treatment by chromic acid solution (Hamon de Fougeray) ulceration : case for diagnosis (StClair 'Thomson)

- see also Naso-pharynr.

- see also Retro-pharyngeal abscess.

Phlegmon of tonsillar fossa simulated by sarcoma of that region (Gaudier: abstract)

Phonation, function of false cords in (Donogany : abstract) $\cdot$.

Photography, stereoscopic, of laryn (Garel : $\quad 100$

Photophobia: a reflex of adenoids (Thomas : abstract) $\quad . \quad 139$

Phthisis, pulmonary: subcutaneous emphysema secondary to laryngeal perforation in phthisical patient (Raviart: abstract) . . . . .

Physiology of ear (Cole : abstract) . $\quad . \quad+\quad . \quad .56$

PIAGET, transformation of alternating into constant current: installation of a silent motor (abstract)

PIeniazek, Professor: cases from his clinic in Hospital of St. Lazar (abstract)

Pin in larrnx (Erger) de Roaldes) for two vears, removed by endolaryngeal methods (A. W.

Plottrikr, adenoid vegetations and diphtheria (abstract)

PLücker on cellulitis of the neck; phlegmona submandibularis acuta (abstract)

Pneumatic treatiment of diseases of ear (G. Navoli)

Pneumogastric nerve: see Nerve (pneumogastric).

Poisons : caustic ; accidental cauterization of larynx by (Courtade) . 93

Politzer (Adam), the extraction of the stapes

$\begin{array}{lll}- & & 66 \\ - & \text { cured case of sinus thrombosis in a girl of nine (abstract) } & \cdot\end{array}$ on case of abscess round the sigmoid sinus, with suppuration of mastoid

PoLlak, a case of complete deafness following a railway accident [collision] (abstract)

Polypus: bloodless operation in cases of typical naso-pharyngeal polypi (Sehmithuisen : abstract)

larnol (Gaudier

muco-fibrous (Wishart Gibb : abstract)

nasal polypi followed by extensive necrosis (W. G. spencer) treated by a new radical method (H. Lambert Lack) with suppuration and (?) absence of maxillary

sinuses (H. Lambert Lack) radical operation for nasal polypi (C. A. Parker). 
I'olypus: operative treatment of fibrous naso-pharyngeal polypi (I)elie: abstract) . ${ }^{\circ}$ presence and treatment of poly in chronic purulent nasal discharges (E. W. Roughton)

Poncer, the geographical distribution of coitre in France (abstract)

Poncet (A.) and BIRARD on the so-called glandular form of cancer of the pharynx (abstract) .

Pons : see Brain.

Potter (E. Furniss), microscopical section of a growth (lymphangioma?) removed from the right rentricular band of a man aged forty

_ a case of post-nasal growth in a woman aged forty-seven, which in his opinion was a persistence of adenoids

growth on each ventricular band in a man aged thirty-nine. case of pharyngeal growth involving the larynx in case of man aged fifty-nine

- on persistent adenoids in a woman aged forty-seren :

- elected to senior staff of London Throat Hospital

shown at the March meeting; with microscopic section of portion of growth removed

Pouch : œsophageal (H. T. Butlin).

Powell (H. Fitzgerald), case of (?) myxofibroma of the post-nasal space. case of tubercular laryngitis in a man aged thirty-one

case of male aged seventeen years, after remoral of fibro myxoma

of the post-nasal region

Pregnancy and labour causing threatening swelling of tumour of the larynx (Ephraim : abstract).

PrICE Bnown (J.), diseasc

- nasal and post-nasal sinechix, 653

Pritchard (Urban), antiseptic purification of the meatus and adjacent parts : both for operations and as a treatment in chronic middle-ear suppuration

- _- specimen of cholesteatoma removed through the meatus, with the patient from whom it was removed . . . . 143

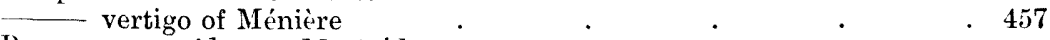

Process, mastoid: see Mastoid process.

Prognosis: prognostic value of Gelle's test (Max Breitung: abstract) . 446

PRoTA $(G$.$) , vegetating tuberculosis of the nose (abstract) . . 215$

Pseudo-hemoptysis arising in naso-pharynx (R. Botey) $\quad . \quad 590$

$\begin{array}{llll}\text { Psychic salivation (P. Hellat) } & \text {. } & \text {. } & 608\end{array}$

Pulmonary lesion: see Lesion (pulmonary).

Puncture (exploratory) in chronic purulent nasal discharges $1 \mathrm{E}$. W. Roughton).

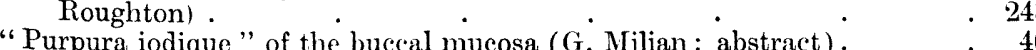

Purulent disease of the temporal bone (Körner: review)

Pus and blood discharged from naso-pharynx for over twelve months (Barclay Baron)

- location of chronic purulent nasal discharges by rhinoscopy (E. W. Roughton) .

Pyæmia (fatal) following mastoid disease and acute otitis media, result of injury in an epileptic (R. A. Wilson)

otitic : diagnosis and treatment of otitic pyemia (J. I)undas Grant)

PyNchon on the offending middle turbinal (abstract).

Quinine Hydrobronide "Tabloid" (new preparation) . . . 347

Quintan (Francis J.), elected Professov of Taryngology and Thinology at the New York Polyclinic

Raczynski on so-called ulcerous angina and its differential diagnosis from diphtheria (abstract). 
Radiographical researches on topographical relations of brain, frontal and maxillary sinuses, and venous sinuses of dura mater to walls of skull (I. Regnier and J. Glover : abstract)

Railway accident [collision] followed by complete deafness (Pollak: abstract) .

RAviart, subcutaneous emphysema secondary to laryngeal perforation in a phthisical patient (abstract)

Recurrent croup : spasmodic ; treatment (M. P. Creel: abstract)

REDARD (P.) and Michel (Frank), deep median furrow of the lower lip and chin, median division of the inferior maxilla, and malformation of the tongue (abstract)

Refrigerants and bleeding in treatment of acute otitis media (Miot: abstract)

Regnier (Paul) and Glover (Jules), radiographical researches on the topographical relations of the brain, the frontal and maxillary sinuses, and the venous sinuses of the dura mater to walls of skull (abstract)

REINHARD (Paul), on late tracheal stenosis after tracheotomy (abstract)

Relaxation of membrana tympani : its pathology (Gruber : abstract)

Resection of trachea in primary carcinoma (Bruns: abstract) .

Resonator of the voice (IV. A. Aikin)

Resonators of roice (W. A. Aikin).

RÉthi (I.), the negative air-douche as an aid to the diagnosis of diseases of the nasal accessory cavities (abstract)

_ - on negative air-douche as diagnostic help in diseases of the accessory cavities of the nose (abstract) .

Retropharyngeal abscess (Traver: abstract).

Reviews: British sanatoria for the of auricular orig (Uelzi) Gould's Year-Book (1900) (Surgery).

Handbook of Laryngology and Rhinology ; parts 21-23 (Heymann) Head (G. P.) and Andrews (Albert H.) the year-book of the nose, throat, and ear (review)

\section{Medical Annual (1900}

Price Brown (J.), diseases of the throat and nose (review)

Sajous's annual and analytical cyclopædia of practical medicine

(disorders of internal ear ; intubation ; laryngitis).

- Tilley (H.), purulent nasal discharges

Rhinitis, atrophic (J. E. Logan)

S. Viollet) advanced case in a young girl (I. A. I.awrence)

laryngitis secondary to rhinitis causing hoarseness in a chaff-cutter

(J. Dundas Grant) $\dot{0}$. . . 164 septic, of childhood, acute (Somers : abstract) $\cdot \quad \cdot \quad \cdot 216$

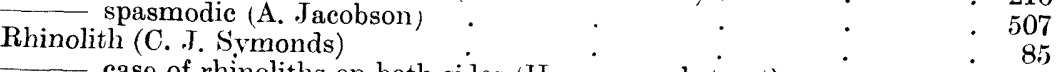

\begin{tabular}{lll} 
Rhinological Society of Paris, proceedings & $\cdot$ & $\cdot$ \\
\hline & & $\cdot$
\end{tabular}

Rhinology, retrospect of (Arthur Sandford) $\cdot{ }^{\prime} \quad \cdot \quad 285$

- successful application of adrenal extract in (Warren : abstract) $\quad \begin{array}{r}1 \\ \hline\end{array}$

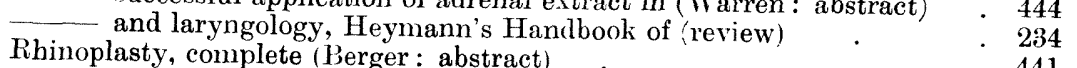

Rhinoplasty, complete (Berger: abstract) . $\quad . \quad . \quad . \quad .441$

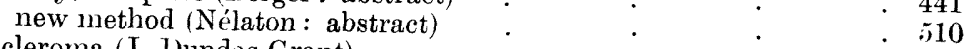

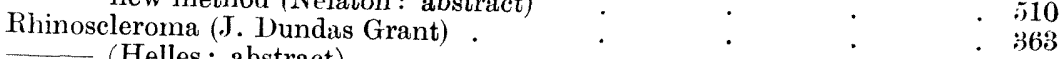

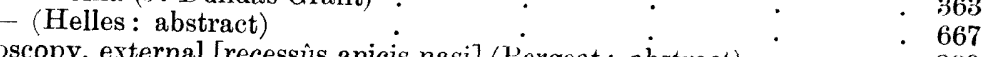

\begin{tabular}{lll} 
Rhinoscopy, external [recessûs apicis nasi] (Bergeat : abstract) & $\cdot$ & $\cdot$ \\
\hline
\end{tabular}

RICARD, aural reflexes in a hysterical W. Roughton) • $\quad \cdot \quad 240$

$\begin{array}{ll}\text { RICARD, aural reflexes in a hysterical patient (abstract) } & \cdot \\ \text { RICE (C. C.) on singular exhibitions of partial paralysis of } & \cdot 454\end{array}$ cords tue to over-use of telephone 


\section{Index.}

Richards, use of gelato-glycerine bougies in treatment of earache (abstract)

Richardson, asthma as a reflex manifestation from abscess of the antrum (abstract) .

Rimini, cerebellar abscess (abstract)

RipaUlt on the treatment of lupus of the nose (abstract)

RIScHAEVAY on case of complete adhesion of the epiglottis with the root of the tongue through luetic cicatrices; the physiology of swallowing (abstract).

Roaldes (A. W. de), case of pin in larynx for two years; removal by endolaryngeal methods

Roderick (H. B.) and Ewart (W.), extensive mediastinal emphysema in a fatal case of laryngeal diphtheria, with remarks on the early and the late variety of emphysema observed in the case after tracheotomy (abstract).

RoE (John O.) on correction of deviations of the nasal septum :

Roentgen rays : illustrations of migratory foreign body by (D. Braden Kyle) importance of application in aneurysm of aorta (Sendziak: abstract) in diseases of the nose, throat, and neighbouring organs (John Macintyre : abstract)

RoGERs, the prevention of nasal catarrh (abstract) a case of empyema of the frontal sinus (abstract)

Rogers' Modified Lozenge (new preparation)

ROPKE on cases of acute osteomyelitis of upper jaw in infants (abstract)

ROSENBERG on some consequences of singers' nodes (abstract) .

Ross (G. T.), laryngeal paralysis (abstract) quarterly retrospect of the department for diseases of throat and nose (abstract)

Roughton (E. W.), case for diagnosis: a boy aged ten suffering from aphonia

the diagnosis and treatment of chronic purulent nasal discharges 238,317

case in which there was a difficulty in removing a tracheotomy tube

Roy (Dunbar), some observations on the prognosis and treatment in the so-called catarrhal deafness (abstract)

Royal Medical and Chirurgical Society

Rupture, multiple, of membrana tympani (Overacker : abstract)

of œophagus from vomiting. with table of hitherto recorded cases (R. L. Bowles and G. R. Turner) when apparently healthy (E. J. McWeeney : abstract)

Sabrazès and Lichtwrtz, fusiform bacillus of Vincent in a case of ulcerous tonsillitis, and in two cases of peribuccal ulceration

Saccus endolymphaticus, formation of a circumscribed inter-dural abscess at the site of (W. Jobson Horne)

SACHs (Richard), operation on the pharrngeal tonsil; hæmophilia; death .

SAENGER on perverse action of the veluim palatinum (abstract)

St. Lazar, Hospital of, cases from clinic of Professor Pieniazek in Hospital of St. Lazar (abstract)

SAJOUS's annual and analytical cyclopædia of practical medicine (review) .

Salicylic acid in treatment of pachydermia laryngis (.J. Fein : abstract) .

Salivation, psychic (P. Hellat)

SANDFORD (Arthur), retrospect of rhinology .

DE SANTI (Philip), case of double uvula

- case of hoarseness and aphonia of long-standing in a girl aged thirteen

- case of obstructed subdermal lymphatics of the face in which frontal and antral disease had been suspected

Sarcoma, alveolar, involving petrous bone, causing paralysis ; successful operation (Charles A. Ballance) 
Sarcoma of carotid sheath; removal; recovery (Scanes Spicer and Stansfield Collier : abstract)

-_ of larynx, complete removal of larynx (J. Dundas Grant) . - specimen of larynx remored on account of (.J. I)undas Grant) of nasal passages (Wurdemain: abstract) of post-nasal space (E. B. Waggett) . of tongue: case (Dorner ; abstract). of tonsil, primary ; successful extirpation through mouth (.J. Walker Downie) of tonsillar fossa simulating phlegmon of that region (Gaudier: abstract) - see also Hibro-sarcoma.

Sarcomatosis, cutaneous; laryngeal complications (Prof. F. Massei :

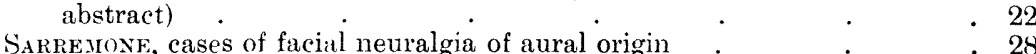

SACrER (R.), contribution to the surgery of the temporal bone (abstract) . 229

SAvorre (Camille), the treatment of chronic pharyngitis $\quad . \quad .600$

Scarlatina followed by erosive angina (Bergé : abstract) $\quad . \quad 328$ otitis media due to (J. M. Mac(allum : abstract) . . 452

scarlet fever: case of membranous angina and membranous vaginitis of loubtfully diphtheritic nature in patient recovering from scarlet fever ( ('. K. Millard : abstract)

- perichondritis laryngea in ( $\dot{H}$. Kraus: abstract)

$\quad \cdot 52$

$\mathrm{S}$ (HECH, on roice affections of singers and professional voice-users (abstract) 340

SCHEIER (Max), on the architecture of the laryngeal cartilages . 601

SCHIfFERs ( $\mathrm{Y}$. ), on a universal notation of acoumetry . . 556

SCHLAciexhitfar ( $\mathrm{Fl}_{\mathrm{r}}$ ), on cases of cystic degeneration of the mucous membrane of the nose and accessory sinuses (abstract)

S'HuID on results of serum treatment of diphtheria in the "Rigaschen Stadtkrankenhause" (abstract)

SCHMIDT (Moritz), early diagnosis and treatment of aortic aneurism

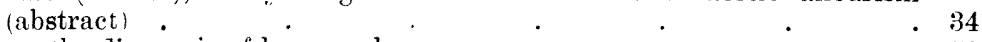

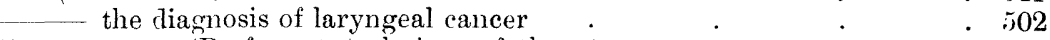

Schumegelow (Professor), technigue of thyrotomy . $. \quad . \quad 505$

Schumthusen. on treatment of laryngeal tuberculosis with the galvanocautery (abstract). - on bloodless operation in cases of typical naso-pharyngeal polypi (abstract). on tuberculoma (large) in naso-pharynx with necrosis of the sphenoid and occipital bones (abstract) . $\quad . \quad 3 \quad . \quad 37$

SichRötTER (H. ron), on tumour of the thyroid (abstract) $\quad . \quad 339$

foreign body in bronchus; removal per vias naturales (abstract) : 340

SCHWABACH, diseases of the ear in pernicious anemia (abstract) . . 454

Schwartze (H.), acquired atresia and stricture of the auditory meatus and its treatment (abstract)

- cases of dangerous sequel: of suppurative otitis media occurring in his otological clinic . . . .

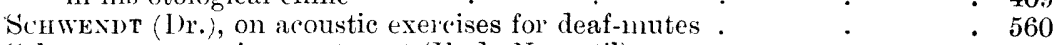

Scleroma : operative treatment (1.. de Navratil) $\quad . \quad 5 \quad$. $\quad$. 599 primary, of the larynx (Baumgarten). $\quad . \quad 5 \quad$. $\quad 326$

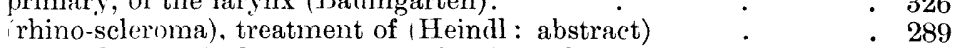

Sclerosis, aural; surgical treatment of (F. Siebenmann and Ricardo Botey)

Sriss (Raiph W.), the atrophic pharynx (abstract) .

SkLigmas (H.), acute bilateral (double) brain abscess after opening the mastoid ; recovery (abstract)

Semilunar canals: see Canals, semilumar.

SEMON (Sir Felix), a diagnostic mistake

- blood-clots simulating laryngeal neoplasms (abstract) . - case of laryngeal (?) whistling pseudo-membranous adhesion in the anterior commissure and 


\section{Index.}

symmetrical thickening below the anterior part of the vocal cords (congenital ?) in a young man .

- cancer (?) of the larynx-stenosis of the a sophagus: from the

Rhino-Laryngologic Casuistic (abstract)

- contribution to the importance of examination of the larynx, as well as application of Roentgen's rays in aneurysm of the aorta . - on diphtheria of the pharynx and naso-pharynx, complicated by multiple abscesses of the tonsils, also by empyemata of both antra of Highmore (abstract) .

- on diagnosis and treatment of suppurative inflammation of the palatine, as well as lingual tonsils, with special reference to peritonsillar abscesses (abstract)

- on question of complications after removal of post-nasal growths (abstract)

Septicemia, auricular, due to bacillus coli and bacillus perfringens (Baup and Stanculéanu: abstract)

Septum, nasal: see Nose

-...- nasi : see Nose.

Sequelæ, dangerous, of suppurative otitis media (Grunert and Zeroni) .

Sequestration of bone around lumen of canal formed by drilling alveolus in antral disease (Lichtwitz). of cochlea in case cured of cerebellar abscess ( $\dot{F}$. H. Waggett)

Serum : diphtheria antitoxin serums treatment of diphtheria (Siegel : abstract)

(Schmidt : abstract). results in "Rigáschen Starltkrankenhause";

SEVESTRE and AUsser, laryngitis complicating measles (abstract) • 445

SHARP (J. Clarence), on use of suprarenal capsule in the nose and throat (abstract) .

Sheath, carotid, sarcoma (Scanes Spicer and Stansfield Collier : abstract) .

Siebenuann (Professor F.), a modification of Körner's plastic in operations for cholesteatoma (abstract)

- on surgical treatment of aural sclerosis

SIEGEL on serum treatment of diphtheria (abstract)

Siegert (F.), on an epidemic of angina lacunaris and its period of incubation (abstract)

Sigmoid sinus: see Sinus, sigmoid.

Silver nitrate: repeated cauterization of pharynx with silver nitrate causing argyrism of skin and mucous membranes (Méneau : abstract)

Singers; disturbances of intonation and loss of voice (Flatau : abstract) .

- voice affections of singers (Schech : abstract) .

Singers' nodes (Rosenberg: abstract)

Singing: vocal troubles in singers and their treatment (Botey : abstract) . 336 Sinus, accessory : insufflator for the accessory sinuses (Lichtwit $\%$ ) 89

- statistical table of 169 autopsies of accessory sinuses (Lapalle) $\quad 92$ disease of, followed by extensive necrosis (IV. G. Spencer) $\quad 370$

(face): surgery of sinuses of face in relation to surgery of orbit (G. Laurens) frontal, anatomy (A. Hartmann) duct (Tue) . catarrh, painful recurrent, due to stenosis of fronto-nasal - $\cdot$ • $\quad$ • 609

(H. presenting features of unusual interest 
Sinus (frontal), double frontal sinus and antral empyema with distension of bridge of nose ( $\mathrm{H}$. Tilley) - external examination and catheterization of, in purulent

relations of frontal and maxillary sinuses to walls of skull (Pographical and J. Glover : abstract)

- (lateral) thrombo-phlebitis : operation without ligature of internal jugular vein ; recovery (J. Dundas Grant)

abstract) - new symptom of obstructive thrombosis (F. Voss:

- recovery from thrombosis of lateral sinus after

opening of sinus and ligature of internal jugular vein (T. Barr and $J$.

H. Nicoll : abstract) .

(S. Lodge, jun.) two cases, one with obscure etiology and pathology

with chronic suppuration of middle ear ; internal jugular vein not ligatured; recovery (A. H. Cheatle : abstract)

recovery (A. H. Cheatle)
(maxillary) : chronic maxillary sinusitis radically cured by surgical treatment (C. Broquet: abstract)

- question of absence of maxillary sinuses in case of nasal polypi (H. Lambert Lack) (nasal accessory) disproportion between frequence of empyema in the living and dead (Lichtwitz: abstract) . (petro-squamosal), anatomy and pathological importance (A. H. Cheatle) (left sigmoid): otitic thrombo-phlebitis followed by extensive trans. ference of thrombotic material in retrograde direction (Biehl : abstract) (sigmoid) surrounded by abscess, without suppuration of mastoid (Politzer)

(sigmoid and lateral), thrombosis six years after scarlatinal otitis media (J. M. MacCallum : abstract)

sinuses in the vallum abstract) ... (sinuses in the vault of the naso-pharynx (Charles Heath)
(sphenoidal), case in which orifice was shown (E. B. Waggett)

Barlow) case of ozæna of probable sphenoidal origin (J. W.

\begin{tabular}{c} 
Barlow) \\
W. Roughton $)$ \\
\hline
\end{tabular} thrombosis : cure without operation (Levy $:$ abstract) :
tract) of sinus of ear cured in a girl of nine (Politzer : abstract) relations to walls of skull (P. Regnier and J. Glover : abstract) Sinusitis, chronic multiple, radical operation for (Taptas) $\quad \cdot 623$

fronto-maxillary, study of (Lubet Barbon and Furet : abstract) $\quad$. 610

-_ relations to ozæna (P. George : abstract) $\quad . \quad 334$

stract)

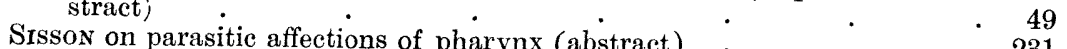

Sisson on parasitic affections of pharynx (abstract) .
Skin : argyrism due to repeated cauterization of pharyn with

(Méneau : abstract).

Skull : radiographical researches on topographical relations of brain, frontal and maxillary sinuses, of dura mater to walls of skull ( $P$. Regnier and J. Glover: abstract)

Smell, loss of : see Anosmia. 
Snare (electric): new electric snare for removal of adenoids (Garel: abstract)

Society of Laryngology, Otology, and Rhinology of Paris

herbe's operation of clearing

Sokolowski, the changes in the upper air-passages by vitia cordis (abstract) - the relation of diseases of internal organs to the disturbances in the upper air-passages (abstract)

Sours-Cohen (J.), on surgical procedures $\quad \cdot \quad \cdot \quad \cdot \quad \cdot \quad \cdot \quad 307$

SONERs, on acute septic rhinitis of childhood (abstract) $\quad . \quad 216$

speculum-holder, nasal and aural (Courtade) $\quad . \quad 93$

SPENCER (Walter G.), case of pharyngo-œsophageal carcinoma . $\quad 150$

-... case of primary atrophic rhinitis commencing in infancy $\quad . \quad 151$

-...- case of thyrotomy for tertiary syphilitic laryngitis . . . 204

- case of extensive necrosis following nasal polypi and sinus disease 370

Sphenoidal sinus: see Sinus, sphenoidal.

SPICER (R. H. Scanes), case of laryngeal perichondritis in a man of twenty.

six, the subject of pulmonary tubereulosis

- case of extensive ulceration of throat for diagnosis $\quad$. laryngeal cases for diagnosis introductory address at section of laryngology and otology, British

Medical Association annual meeting, $1900 \quad . \quad . \quad 463$

- discussion on intra-nasal treatment of ear disease $\quad . \quad 484,487$

- and Collier (H. Stansfield), sarcoma of the carotid sheath ; removal

of the growth, together with portions of the carotid arteries, internal jugular vein and pneumogastric nerve ; recovery (abstract)

Spokeshave (Carmalt-Jones'), for removal of septal spurs (W. Gibb : abstract)

Spray: the Ashton spray

Spur, bony, from ethmoid (R. Lake)

$\cdot \cdot \cdot 25$

STACKE's operation: eighty successive cases (P. Jakins : abstract) $\quad 447$

Stammering in a young man (case shown by Mr. Atwood Thorne for: Dr. William Hill)

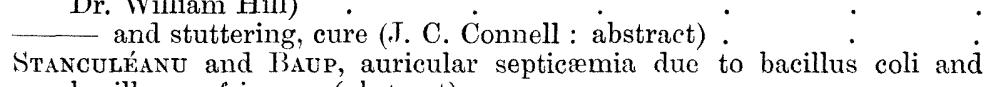
bacillus perfringens (abstract) .

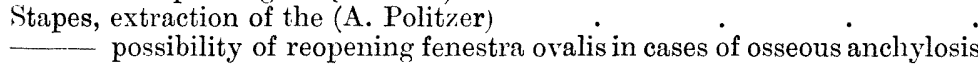
of stapedo-vestibular articulation (G. Faraci) synechiotomy of stapes for improring hearing in chronic suppurative otitis media residua (E. B. Dench : abstract) .

Statistics of the dangerous complications of suppurative ear diseases and of operations on the mastoid process (M. Teichmann : abstract)

statistical results and methods of treatment (1). B. Delavan) sinus (Luc) .

- - of larynx, due to complication of thyroid cartilages ( $\dot{\mathrm{E}}$. Mayer : abstract) treated by electrolysis in patient who had worn tracheal cannula sixteen years (M. Boulay and J. Boulai) . nasal (B. S. Booth : abstract) of cesophagus (Holzknecht: abstract) (Sendriak: abstract) of pharynx, severe, not of syphilitic origin (Swiatecki : abstract) of trachea (case shown by Mr. Stephen Paget for Dr. Pasteur) late, of trachea after tracheotomy (P. Reinhard : abstract)

Sterno-mastoid and trapezius muscles (left): paresis in case of hysterical paralysis of left vocal cord (C. Chauveau)

STETTER on chronic dry myringitis and its treatment (abstract) . 113

Stewart (IV. R. H.), extra-laryngeal (?) malignant growth (shown by Mr. E. B. Waggett) case of swelling about the bridge of the nose (shown by Mr. E. 13 . Waggett) 
Stomach, endoscopy of (G. Kelling : abstract)

Stomatitis, ulcero-membranous, with Vincent's usiform bacilli and spirilla

(A. Panoff : abstract)

Streptococcus causing an epidemic of simple angina (L. le Damany: abstract)

Streptothrix : tonsillitis streptothricia (P. Hellat)

Stricture, acquired, of auditory meatus (H. Schwartze : abstract) of osophagus: case under tubage for twelve months (C.J.Symonds)

Strychnine in treatment of nasal hydrorrhoea (Lermoyez: abstract)

Stuttering and stammering, cure (J.C. Connell: abstract)

Sutrez de Mendoza (Dr.), application to nasal surgery of instruments used in dentistry new instruments. on radical cure of nasal obstruction (abstract).

Suppuration of ear, acute purulent, special danger in elderly people ( 3 .

Heine : abstract)

- ethmoidal and sphenoidal suppuration, diagnosis and treatment

(E. WV. Roughton)

of middle ear, acute and chronic: bacteriological and clinical studies

in complications of (Leutert Konigsberg: abstract) - and brain tumours (B. Hessler : abstract) chronic, of middle ear, and thrombosis of lateral sinus; operation ;

recovery (A. Cheatle)

collowed by abseess of cerebellum (W. Milligan)
adjacent parts (U. Pritchard)

adjacent parts (U. Pritchard) with thrombosis of lateral sinus (A. H. Cheatle:

abstract) chronic, of right maxillary antrum and anterior ethmoidal cells

(P. G. Goldsmith : abstract) . . . (intermittent) for six years, following scarlatinal otitis media (J. M.

MacCallum : abstract)

- in labyrinth : surgical treatment (Kömer : abstract) $\quad \cdot$

(nasal) : purulent nasal discharges (H. Tilley : review) :

Suppurative cyst of turbinal bone (H. A. Davis)
disease of the middle ear (chronic), selection of cases for the com-

plete mastoid operation (A. E. Cumberbatch) .

ear diseases; statistics of dangerous complications (M. Teichmann: abstract)

Suprarenal capsule; its use in the nose and throat (J. C. Sharp: abstract) 335

-- - extract: see Extract, suprarenal.

Surgery, Gould's Year-Book (review)

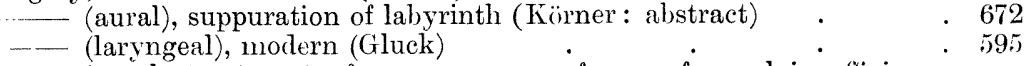

(nasal), treatment of some common forms of nasal insufficiency

(L. H. Pegler) application of instruments used in dentistry to (Suarez.

de Mendoza) of sinuses of face in relation to surgery of orbit (G. Laurens)

Surgical procedures (J. Solis-Cohen)

Suture, early, of retro-auricular incision after mastoid operation (Botey: abstract) . . . . . . .

Swallowing difficult in case of hysterical paralysis of left vocal cord (C.

Chauveau) . physiology of (Pischaevay: abstract)

S'welling about briage of nose (case shown by Mr. E. 1s. Waggett for Mr. W. R. H. Stewart) 


\section{Index.}

SWIATEcki on case of severe stenosis of pharynx, not syphilitic in origin

(abstract)

- rhinolith

Synechia, bridge-like synechice, between septum and inferior turbinated

body (J. Dundas Grant) . $\quad$. $\quad . \quad$. $\quad .164$

- — (nasal) : (J. Dundas Grant) ․ . . . . . 664 - nasal and post-nasal synechiæe (J. Price-Brown) $\quad . \quad 653$

Synechiotomy of stapes for improving hearing in chronic suppurative otitis media residua (E. B. Dench : abstract) . . . 108

Syphilis: congenital syphilitic ulceration of nose (Wyatt Wingrave) . 665 - hereditary, causing hypertrophic laryngitis (StClair Thomson) . 366 innocently-acquired syphilitic infection of the throat (F. R. Packard : abstract) syphilitic tumour of the tonsil simulating malignant neoplasm

(Ciechomski : abstract) tertiary, of nose, pharymx and larynx (Tresilian) specific ulceration of ala nasi (J. Dundas Grant) . thyrotomy for tertiary syphilitic laryngitis (W. G. Spencer) unusual form of ulceration of throat in case of (Wyatt Wingrave) .

Tabes, case with almost complete laryngoplegia (Sir F. Semon) .

laryngeal crisis in tabetics in relation with the other visceral crises

(Touche: abstract) . . . . . 55

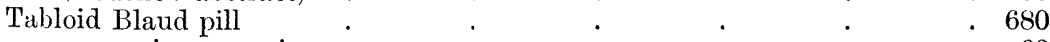

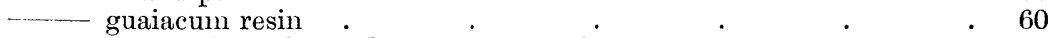
quinine hydrobromide (new preparation) $\quad . \quad$. $\quad .347$

ThanturR (D.), tuberculosis of the tongue (abstract) $\quad . \quad 5 \quad . \quad 212$

TAPTAs, hysterical deafness cured by suggestion (abstract) $\quad . \quad$. 454

- on the radical operation for chronic multiple sinusitis . $\quad .610$

Taste: function of soft palate (Mariau : abstract) $t$. $\quad . \quad 395$

TAves on strength and preservation of diphtheria antitoxin (abstract) . 287

Teeth: examination of upper teeth in chronic purulent nasal discharges (E. W. Roughton)

Teichuann (M.), statistics of the dangerous complications of suppurative ear diseases and of operations on the mastoid process (abstract)

Telephone: over-use of, causing partial paralysis of vocal cords (C. C. Rice)

Temporal bone: contribution to the surgery of the temporal bone ( $\mathrm{R}$. Sateler: abstract)

- from a case of leukimia (Dr. Gomperz) $\quad \cdot \quad \cdot \quad 32$

$\ldots+$ purulent disease (Körner : review) . $\quad . \quad 58$

TExiER and BaR, contribution to the study of nasal tuberculosis . $\quad . \quad 611$

Therapeutics: abstracts of literature $. \quad . \quad . \quad 455$

Thickening, symmetrical, below anterior part of vocal cords (Sir Felix

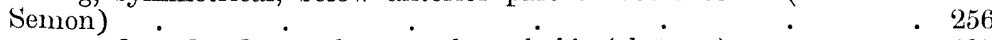

Thomas on adenoid reflexes : hiccup, photophobia (abstract) $\quad . \quad 398$

Thorson (StClair), female aged twenty-four with enlargement of nose $\quad . \quad 35$

male aged fifteen with enlargement of nose . . . . 35

- case of ulceration of the pharynx for diagnosis . . . . 204

cleft soft palate and well-marked post-nasal adenoids . . 205

- case of a female aged twenty-three with obstruction of one nostril

from antral affection of uncertain character ${ }^{2}$ case of a girl with hereditary syphilis causing hypertrophic laryngitis, and showing recesses in the naso-pharynx produced by the approximation of the remains of Luschka's tonsil and the Eustachian

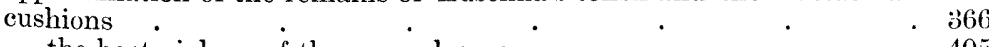

- the bacteriology of the normal nose $. \quad+\quad . \quad+\quad . \quad 405$

Thonne (Atwood), nasal case for diagnosis . $\quad . \quad 35$ - a case of stammering in a young man (shown for Dr. William Hill) 165

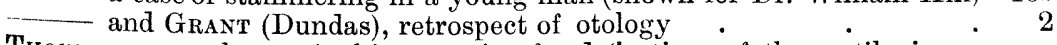

Thonner, remarks on Asch's operation for deflections of the cartilaginous septum (abstract) . . . . 
Thrasher (A. B.), on fibroma of the larynx . . . . 310

Throat: conditions of throat and larynx simulating and predisposing to tuberculosis (Lennox Browne). . . . (cut) two cases of, with opening of air-passage (E. R. C. Earle: abstract)

(diseases): cases from Clinic of Professor Pieniazek in Hospital of St. Lazar (Bourowicz: abstract)

- quarterly retrospect of department for ( $\dot{G}$. T. Ross : abstract) - innocently acquired syphilitic infection of the throat (F. R. Packard: abstract) - Röntgen rays in diseases of the nose, throat, and neighbouring organs (John Macintyre: abstract) ulceration, extensive: case for diagnosis ( $\mathrm{B}$ ' scanes Spicer) - unusual form in patient the subject of syphilis (Wyatt Wingrave) use of suprarenal capsule in the nose and throat (J. C. Sharp: abstract) Year-Book (G. P. Head and A H. Andrews: review) • and nose, diseases (J. Price-Brown : review) .

Thrombo-phlebitis of lateral sinus treated by operation without ligature of internal jugular vein : recovery (J. Dundas Grant) of left sigmoid sinus followed by extensive transference of thrombotic material in retrograde direction (Biehl : abstract) ombosis: extensive transference of thrombotic material in retrograde direction after otitic thrombo-phlebitis of left sigmoid sinus (Biehl: abstract) of lateral sinus, obstructive: a new symptom (F. Voss: abstract) cure without operation (Levy : abstract) in case of chronic suppuration of middle ear: internal jugular vein not ligatured : recovery (A. H. Cheatle : abstract) of otitic origin (H. Knapp : abstract) recovery after opening of sinus and ligature of

internal jugular vein (T. Barr and J. H. Nicoll : abstract) •

(S. Lodge, jun.) with chronic suppuration of middle ear; operation : recovery (A. H. Cheatle) septic, of lateral and longitudinal sinuses with pus in intact middle ear (IV. Jobson Horne) of sinus cured in a girl of nine (Politzer : abstract)

of sigmoid and lateral sinus, occurring six years after scarlatinal otitis media (J. M. MacCallum : abstract)

Thyroglossal duct: persistence of the lower portion (A. T. Bazin: abstract)

Thyroid cartilages : complication of the thyroid cartilages causing laryngeal stenosis (E. Nayer: abstract) . duct: its removal (Armstrong: abstract) gland : effect of iodine upon (L. Gautier : abstract) new growth in right lobe (Tresilian) tumour of the thyroid (H. v. Schrötter: abstract) (T. M. Manley: abstract)

Thyrotomy, effects, immediate and remote (Goris) . for tertiary syphilitic laryngitis (W. G. Spencer) indications (Sir F. Semon)

Trluey (Herbert), specimen of large cholesteatoma removed from the mastoid in a boy aged fourteen . . . . . . $\quad .144$ specimen of a bony cyst of middle turbinate bone $\quad . \quad$. 154 case of tumour of nasal septum . $\quad . \quad 265,369$ on chronic purulent nasal discharges: their diagnosis and treatment 317 purulent nasal discharges: their diagnosis and treatment (review) 344 six cases of frontal sinus empyema . . . $\quad 367$

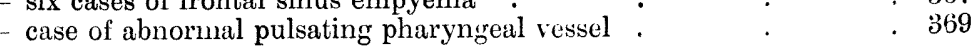


TILLEx (Herbert), case of nasal angiosarcoma shown at last meeting case of chronic ethmoiditis simulating so-called "cleavage" of middle turbinate

operation for frontal sinus eunpyenta

- case of chronic frontal sinus empyema cured by radical external operation . case of double frontal sinus and antral empyema with great distension of bridge of nose

case of pedunculated tonsil

- discussion on intranasal treatment of ear disease

- two cases of chronic frontal sinus empyema presenting features of unusual interest

- chronic empyema of the frontal sinus, with notes on the treatment of fourteen cases (abstract)

Tongue: adhesion, complete, of the epiglottis with the root of the tongue through luetic cicatrices (Rischaevay: abstract)

heniatrophy (L. A. Parry : abstract)
malformation, with deep median furrow of lower lip and chin and median division of inferior maxilla (P. Ledard and Frank Michel : abstract)

- papillomatous condition (J. B. Ball) $\cdot{ }_{-} \quad \cdot \quad \cdot \quad \cdot$

- sarcoma (Dorner : abstract). $\quad .$.

- tuberculosis of (D. Tanturri: abstract)

larynx (Didsbury)

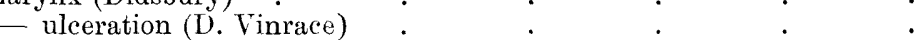

Tongue-depressor : modifications of counter-pressure tongue-depressor (Courtade) .

Tonsil : cysts of the tonsils (Mounier : abstract) . . extirpation of upper half only effectual preventive against phleg. monous tonsillitis (K. Botey).

- faucial : acute ulcer (Wyatt Wingrave) hypertrophy, treatment by morcellement (Ruault) . importance of upper portion of tonsil and of supra-tonsillar fossa in xtiology of phlegmonous peritonsillitis (R. Boter)

lingual : enlargement of lingual tonsils in case of secondary syphilis (H. J. Davis)

- Luschka's : approximation of remains of Luschka's tonsil and Eustachian cushion producing recesses in naso-pharynx (StClair Thomson) . lympho-sarcoma of (Gaudier. pedunculated (H. Tilley) . • . . 433 pharyngeal, operation on pharyngeal tonsil, hxmopliilia; death

(R. Sachs).

- removal of tonsils benefiting epilepsy (L. Browne) $\quad \cdot \quad \cdot \quad \cdot 66$

sarcoma, primary (J. Walker Downie) (Gaudier : abstract).

- - suppurative inflammation of palatine and lingual tonsils; peritonsillar abscesses (Sendziak: abstract). - syphilitic tumour of the tonsil simulating malignant neoplasm (Ciechomski : abstract) . . . . - treatment of digestive disorders associated with chronic tonsillitis (Aviragnet : abstract) . . . . . 327

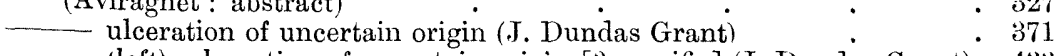

(left), ulceration of uncertain origin [? specific] (J. Dundas Grant) 433

Tonsillitis, acute : pathological histology (Goodall : abstract) . 96 
Tonsillitis streptothricia (I'. Hellat)

Pacis 596

ulcero- or eroso-membranous : presence of short variety of Lïfller: bacillus in exudate of ulcero- or eroso-membranous tonsillitis following operation (Glover : abstract) ulcerous, fusiform bacillus of lincent in case of (Lichtwitz and Sabrazès). . . . a the

Tonsils, enlarged, and adenoids, and their removal (i). J. G. Wishart: abstract

— hemorrhage from a peritonsillar abscess (W. F. Chappell) hypertrophy of tonsils (H. Cuvellier) $\quad . \quad 593$ multiple abscesses of tonsils in diphtheria of pharynx and nasopharyxi (Sendziak : abstract). question of internal secretion Masini $\cdot \quad \cdot \quad 327$

tonsillar and circumtonsillar abscess (G. A. Leland : abstract) . 328

Topography of facial nerve in its relation to mastoid operations (R. $\mathbf{1}$ ). Joyce

Touche, the laryngeal crisis in tabeties in relation with the other visceral crises (abstract)

Trachea, cancer of (xsophagus spreading to (Appert : abstract) . compressed by an aneurism of the arch of the aorta; paralysis of the abductors simulated (Courtade : abstract)

intra-tracheal injections in treatment of laryngeal tuberculosis

(L. Vacher) nembranous occlusion of (jobinie. a bstract)

resection of, in primary carcinoma (Bruns: abstract).

stenosis (case thostract)

late

late stenosis of trachea after tracheotomy (I'. Reinhard : abstract)

tracheal injections in treatment of pulmonary tuberculosis ( $T$.

Morris Murray)

tumours of the trachea (J. Lemoine: abstract)
and larynx : cancer, palliative treatment; use of rubber catheter. as tracheal camnula (A. Courtale)

Tracheotomy apart from croup in the child and adult (A. Lorgnon: abstract) . . . . . .

_ followed by late tracheal stenosis (P. Reinhard: ahstract) - B3̈

Tracheotomy tube, case in which there was difficulty in removing (E. W: Roughton). small modifications (Hotey: abstract)
Transillumination for cases of chronic purulent nasal discharges (E. IV.
Roughton).

Transilluminator for frontal sinus (í . Furet)

Trapezius and sterno-mastoid inuscles, left, paresis in case of hysterical paralysis of left vocal cord (C. Chauveau)

T'iaver: retropharyngeal abscess (abstract).

Tresilin, demonstration of two cases: 1. Tertiary syphilis of nose, pharynx and larynx; 2. Large new growth in the right lobe of thyroid gland

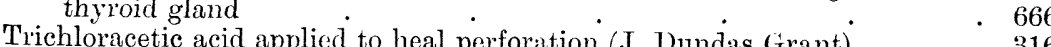

Tubage without permanent surveillance (Eseat: abstract)

Tube, trach $\quad$. 220

'Tubercle of the larynx (C. J. Symonds)

Tuberculoma in naso-pharynx with necrosis of sphenoid and occipital bones (Schmithuisen : abstract)

'Tuberculosis; British sanatoria for open-air treatment (review). conditions of throat and larynx simulatiug and predisposing to
tuberculosis (Lennox Browne). acute, of middle ear (Gaudior : abstract)

laryngeal affection in tubercular patient for diagnosis (G. C. (atheart) laryngeal, an apparatus for treatiment by inhalations (P. Lacroix) Grant) intercordal (tubercular) tumour of larynx (J. Dundas 
Tuberculosis, laryngeal, primary (S. Bernheim)

treatment (Kassel : abstract) . $\quad \cdot \quad \cdot \quad \cdot 601$

$-\quad$ treatment by intra-tracheal injections (L. Vacher) $\quad . \quad 613$

abstract) of cough and dysphagia in (W. Freudenthal:

- - of laryngeal tuberculosis with the galvano-cautery

(Schmithuisen : abstract) . .

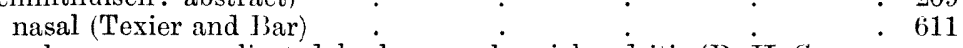

pulmonary, complicated by laryngeal perichonditis (R. H. Scanes

Spicer) treated by tracheal injections $\cdot 45$

\begin{tabular}{ll} 
theated by tracheal injections (T. Morris Murray) & 312 \\
\hline &
\end{tabular}

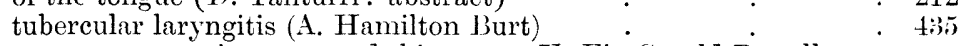

435 perforation of palate (Grossarl : abstract) . . 96

Mr. Lake) ulceration of larynx (specimen shown by Mr. Bergin for

- tuberculous ulceration of pharynx and lower lip (.j. Dundas

Grant) . . . . . . 86

- infection through the nose (G. Liaras : abstract).

vegetating of the nose (G. Prota : abstract) . . . 215

Tumour, fibrous, of lower jaw (T. M. Manley : abstract) . 617

- - in neck containing gas (Guinard : abstract) . . . . . 446

laryngeal, threatening swelling from pregnancy and labour

(Dr. Ephraim: abstract) • . . . . . 219 - benign tumours (Ingersoll ; abstract) $. \quad 5 . \quad 5104$ - intercordal (tubercular) (J. Dundas Grant) . . . 433

- of medulla and pons, causing deafness and other remarkable

symptoms (A. A. Gray) . $\quad . \quad . \quad$. $\quad .29$ of nasal septum (angiosarcoma) (Herbert Tilley) $\quad . \quad 265,369$

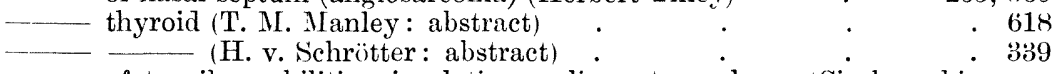

- of tonsil, syphilitie, simulating malignant neoplasm (Ciechomski: abstract)

Tumours of brain and middle-ear suppuration (H. Hessler : abstract) . 672

- malignant, of mucous membrane of pharynx, nose and larynx,

treatment by chromic acid solution (Hamon de Fougeray).

of a'sophagus removed by subhyoid pharyngotomy (IF. Permewan:

abstract) bury)

voluminous, of the base of tongue obstructing larynx (Dids-

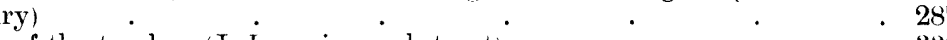

The trachea (J. Lemoine : abstract)

Turbinal bodies, surgery of, with new method of operating (J. E. Boylan). 313

bone, suppurative cyst of (H. A. Davis) . . . 260

- middle, offending (P'ynchon : abstract) $\quad . \quad$. $\quad .216$

Turbinals, inferior, extreme hypertrophy (H. A. Davis) $\quad: \quad$. 261

Turbinate bone: bulbous middle turbinates (R. Lake) . $\quad . \quad 5257$

- _ (J. l'ayson Clark) . . . . 309

(middle) bony cyst of (H. Tilley) : $\quad . \quad 154$

(H. Tilley) "cleavage" simulated by case of chronic ethmoiditis

(H. Tilley) . $\quad . \quad . \quad . \quad .635$

TURNer (A. Logan), a specimen of acute cedema of the larynx . . 373

TurNer (G. R.) and Bowles (R. L.), on case of rupture of a'sophagus caused by vomiting : table of hitherto recorded cases . . 250

Turner (W. Aldren), the central connections of the auditory nerve $\quad . \quad 131$

Tympanic membrane, early paracentesis of, important in certain eases of otitis media acuta (R. Fullerton: abstract)

Tympanum: large heart-shaped perforation of membrana tympani, showing carotid artery in girl aged seventeen (Marx) . . . 323

-___ multiple rupture of membrana tympani (Overacker : abstract) $\quad . \quad 57$

- pathology of relaxation of membrana tympani (Gruber : abstract) 109

Typhoid fever: laryngeal occlusion in (E. B. Waggett) . . 431 
Tyridianoixi oralis (reopening fenestra ovalis in cases of osseous anchylosis of stapedo-restibular articulation) (G. Faraci)

Tleer of mouth, perforating (Compaired : abstract) . $\quad$. $\quad .440$ acute, of faucial tonsil (Wyatt Wingrave) . $\quad . \quad . \quad 81$

Ulceration of epiglottis (Fitzcerali l'owell).

- laryngeal (E. Latw)

. $\cdot 346$

__... (case shown by T)r. H. J. Davis for Mr. S. Paget) . 39:

- tulsercular (specimen shown by Mr. Jergin for Mr. Iake). 435

(nasal) in cases of chronic purulent nasal discharges (E. IV.

Roughton) .

of alie nasi (C. A. Parker) tertiary specific (J. Joundas Grant)

(peribuccal), fusiform bacillus of Vincent in two cases of peribuccal

ulceration (Lichtwit $\%$ and Sabrazes)

of pharynx: case for diagnosis (StClair Thomson)

92

204

86

of throat, extensive: case for diamosis (R. H. Seanes Spicer) . 263

of tongue (D. Vinrace) . . . . . . 663

of tonsil of uncertain origin (J. Dundas Grant). . . $\quad$ 371 (? specific) (T. Dundas Grant) . . $43{ }^{\circ}$

unusual form in throat of patient, the subject of syphilis (Wyatt

Wingrave) .

(of vocal cords) of false cords, true cords, and interarytwnoid region (specimen shown by $\mathrm{Mr}$. Bergin for Mr. Lake)

VACHER, treatment of acute and chronic suppurative otitis with formol (abstract) . . . . . . . . . 5s

- treatment of maxillary, ethmoidal, and frontal sinusitis . . 612

VACHER (L.), treatment of laryngeal tuberculosis by intra-tracheal injec-

tions
Vaginitis, membranous, of doubtfully diphtheritic nature occurring in
patient convalescing from scarlet fever (C. K. Millard: abstract)

VALUDe, electric treatment of exophthalmic goitre (abstract)
VAschide and VAN MeLLE on a new hypothesis as to the nature of the

VAschide and Van MeLle on a new hypothesis as to the nature of the
physics of odours (abstract) .

Vegetations, adenoid, and diphtheria (Plottier : abstract) $\quad$. 95)

Ven (jugular): removal of portion of internal jugular vein together with sarcoma of carotid sheath (Scanes Spicer and Stansfield Collier: abstract) - internal jugular, ligatured in case of thrombosis of lateral sinus ; recovery (T. Barr and J. H. Nicoll: abstract)

ligature not practised in operations for thrombo. phlebitis of lateral sinus; recovery (J. Dundas Grant) tion and thrombosis of lateral sinus; recovery (A. H. Cheatle) not ligatured in case of chronic suppuration of middle ear with thrombosis of lateral sinus; recovery (A. H. Cheatle : abstract

\section{(A. Brown Kelly)}

Ters (J.), suppuration of the accessory nasal cavities, and their importance in general practice (abstract) . . . . . . . 9

Ventricular band: growth on each (E. Furniss Potter). . . 165 right: microscopical section of growth (? lymphangioma) removed from (E. Furniss Potter)

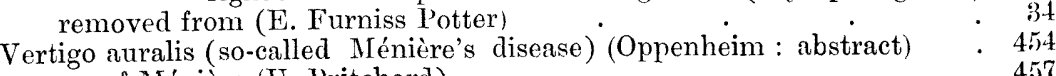


Vessel, pharyngeal, abnormal pulsating (H. Tilley)

VINCENT's spirillæ and bacilli (fusiform) in diphtheritic and ulcerous angina

(J. Freyche : abstract)

(A. Panoff : abstract) in ulcero-membranous angina and stomatitis see also Bacillus.

VIollet (S.) and Mrslay, bacteriological examination of four cases of atrophic rhinitis (abstract)

Vinrace (Dennis), case of ulceration of the tongue $\quad . \quad$.

Viscera: laryngeal crisis in tabetics in relation with the other visceral crises (Touche; abstract)

Vitia cordis causing changes in upper air-passages (Sokolowski : abstract) .

Vocal cord: chorditis vocalis inferior hypertrophica; cure and relapse

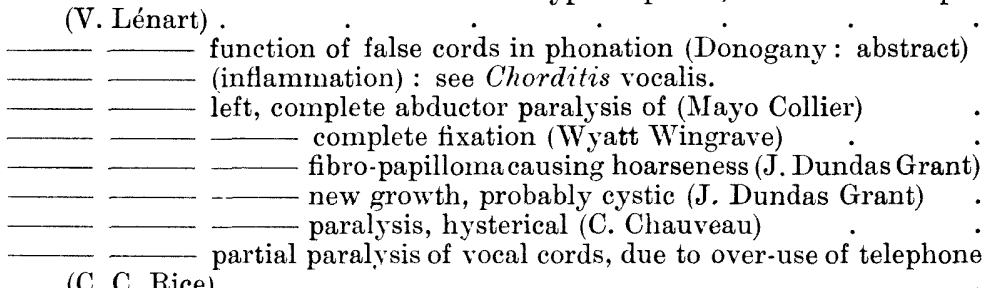
(C. C. Rice) function of false cords in phonation (Donogany: abstract)
(inflammation) : see Chorditis vocalis.
left, complete abductor paralysis of (Mayo Collier)
complete fixation (Wyatt Wingrave)
fibro-papillomacausing hoarseness (J. Dundas Grant)
new growth, probably cystic (J. Dundas Grant)
partial paralysis of vocal cords, due to over-use of telephone
paralysis, hysterical (C. Chauveau) symmetrical thickening below anterior part of vocal cords (congenital ?) (Sir Felix Semon) ulceration of false cords, true cords, and interarytenoid region (specimen shown by Mr. Bergin for Mr. R. Lake)

Vocal nodules (O. Chiari).

Voice altered for over thirty-five years in case of laryngeal growth (anterior commissure) (Hector Mackenzie)

certain vocal affections (Castex)

disturbances of intonation and loss of voice in singers (Flatau: abstract) .

resonators of (W. A. Aikin).

restoration, after incomplete removal of fibro-papilloma of vocal cord (J. Dundas Grant)

voice affections of singers and professional voice-users (Schech: abstract) see also Phonation.

Voss (F.) a new symptom of obstructive thrombosis of the lateral sinus

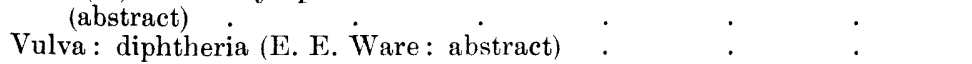

WAGget (E. B.), case of sarcoma of the post-nasal space
extra-laryngeal (?) malignant growth (shown for Mr. W. R. H. Stewart) : growth or granuloma of the epiglottis for diagnosis case of swelling about the bridge of the nose (shown for Mr. W. R. H. Stewart) case of sequestration of cochlea in a man cured of cerebellar abscess case of bulbar paralysis case of laryngeal ocelusion in typhoid fever case of laryngeal occlusion in typhoid fever

case showing the oritice of the sphenoidal sinus on a case of Bezold's complication of suppurative mastoiditis

WARREN, the successful application of adrenal extract in rhinology (abstract) 444

Weber (F. Parkes), on acute Ménière's symptoms in spleno-medullary leucocythæmia, with special reference to the anatomical changes found in acute leucocythæmic affections of the ear (with pathological report on case by R. Lakel. 
WEgLENski, essay on rational treatment of laryngeal tuberculosis (abstract)

Weissman, acute mastoiditis discharging into the meatus (abstract)

Wertherm (Edmund) on complications following intranasal operations (abstract)

WhistLer, the late William MacNeill, ubituary notice.

Whistling, laryngeal (?) (Sir Felix Semon)

Whooping-cough, bromoform treatment (Feer: abstract)

Who's Who (review)

Williams (P. Watson), stereoscopic lantern slides of anatomical and pathological preparations of larynx, pharynx, nose and its accessory cavities - a new universal laringeal forceps

- discussion on intranasal treatment of ear-disease on pathology and treatment of toxic paralysis of the larynx

Wilson (R. A.) mastoid disease, acute otitis media and præmia occurring in an epileptic as the result of injury (abstract)

Wringave (Wyatt), a case of epithelioma of the left ary-epiglottic fold in a man aged sixty-five.

.

case of acute ulcer of the faucial tonsil

- case of paresis of soft palate

- lupus of fauces and larrnx.

a case of complete fixation of the left vocal cord

an unusual form of ulceration of the throat in a patient the subject of syphilis .

case of bilateral abductor paralysis

microscopical specimen of growth removed by larrngotomy by Mr.

Lennox Browne

- economy in the employment of cocaine

- case of congenital syphilitic ulceration of the nose in a female aged twenty

Wintermantel (A.) and MANASse (P.), report of seventy-seven radical operations (abstract).

WISHART (D. J. Gibb), observations on adenoids and enlarged tonsils, and

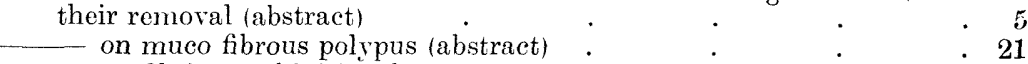

Woakes (Claud). bullet-wound in head; removal of bullet from the nose twenty months afterwards (abstract)

WoolacotT (F. J.). diphtheritic paralysis in cases treated with antitoxin (abstract).

WURDEMAN on sarcoma of nasal passages (abstract) .

X-ray : see Röntgen rays.

Yearsley (P. Marleod), elected full surgeon to Royal Ear Hospital, London

- case of malignant disease of pharynx and larynx $\quad 348$

- an anomalons case of central hemorrhage, connected with increased pressure in the ear. due to violent coughing

- experiments on ancsthesia of the semicircular canals of the ear by

Professor G. Gaglio. Translated by Macleod Yearsley

ZERoNi and GRUNERT, cases of dangerous sequela of suppurative otitis media occurring in Professor Schwartze's Otological Clinic in the University of Halle during the last two years 